\title{
Report of the 20th European Stroke Conference, Hamburg, May 24-27, 2011
}

\section{M.G. Hennerici}

Department of Neurology, UMM, University of Heidelberg, Mannheim, Germany
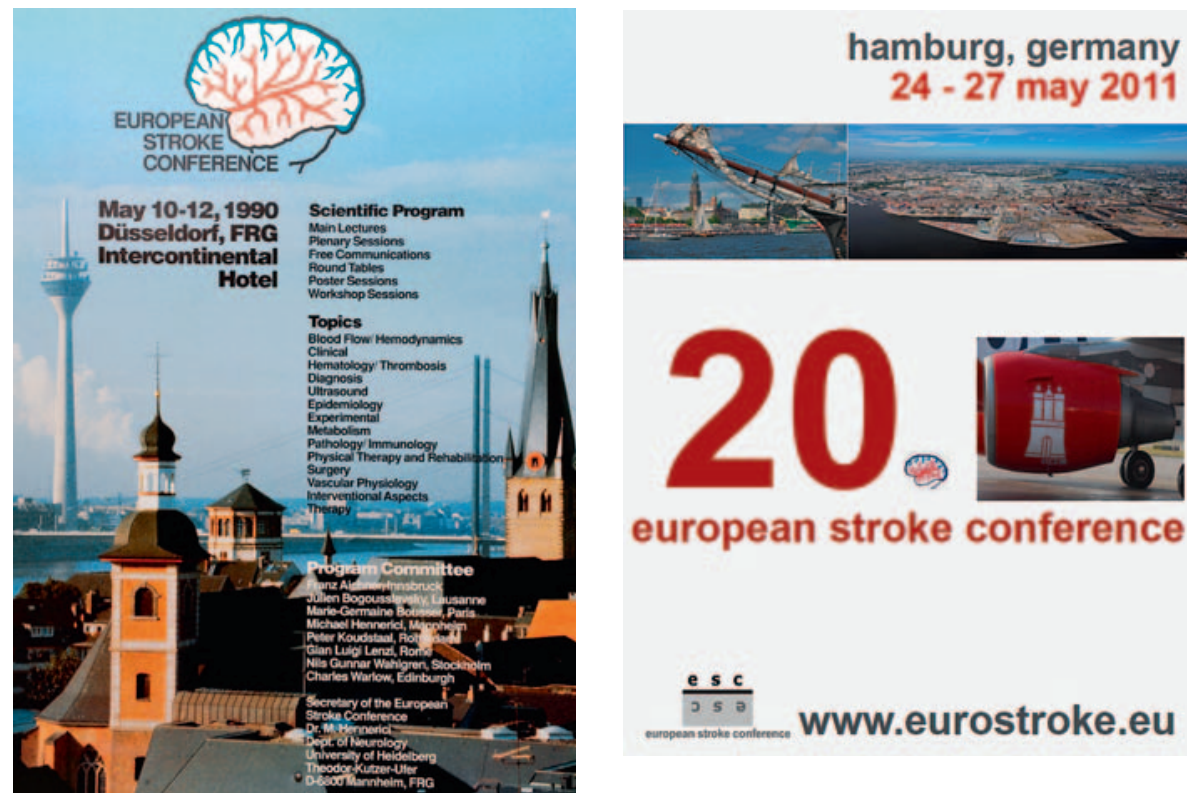

The 20th meeting of the European Stroke Conference (ESC) was held in Hamburg, Germany, May 24-27, 2011. Weather conditions were excellent and the programme of the two-decade anniversary of the ESC has increased to top levels never before reached: while the first meeting was organised in Düsseldorf, Germany (May 10-12, 1990) and included 190 abstracts presented from 28 countries (55 oral and 135 poster presentations), in $2011 \mathrm{ab}$ stract submission had increased to 1,342 from 64 countries, which resulted in 312 oral and 830 scientific poster presentations covering over 20 subjects of stroke research. Among the series of eleven satellite symposia, ten teaching courses, three joint symposia of stroke-related societ- ies, two educational symposia, eight mini-symposia and six newly organised academic symposia - all very well attended by more than 3,000 registered clinicians and basic scientists with interest in stroke research from all around the globe - we selected two for this Conference Report, nicely demonstrating the broad scope of topics addressed as well as the success made through recent research.

The editor and publisher of Cerebrovascular Diseases are grateful for the kind and timely cooperation of the authors to prepare manuscripts of their presentations.

Michael G. Hennerici

Chairman Programme Committee ESC Editor Cerebrovascular Diseases

\section{KARGER}

Fax +41613061234 E-Mail karger@karger.ch www.karger.com
(C) 2011 S. Karger AG, Base

$1015-9770 / 11 / 0326-0589 \$ 38.00 / 0$ 


\section{Stroke and Environmental Changes 20th European Stroke Conference, Hamburg, Germany, May 2011 Educational Symposium 2}

\section{1 \\ Meteorological Changes and Stroke \\ J. Dawson, M.R. Walters \\ College of Medicine, Veterinary and Life Sciences, Institute of Cardiovascular and Medical Sciences, Western Infirmary, Glasgow, UK}

The majority of stroke events, some $80-90 \%$, can be explained by simple models that incorporate traditional cardiovascular risk factors [1]. It is possible that meteorological factors, such as ambient temperature or barometric pressure, account for a proportion of the unexplained risk. Further, these environmental factors may influence traditional risk factors and explain why cerebrovascular events occur at particular times. For example, why does a diabetic man with hypertension suffer a stroke on a given day rather than the many others throughout which he has been at increased risk?

We already know that other variables in the external environment influence stroke risk. Incidence of stroke is higher on Mondays [2] and may reflect either a stress response (for example increased catecholamine secretion) [3] or relatively poor concordance with preventative treatment regimens at weekends. Further, the onset of stroke is most common in the morning and may reflect welldocumented circadian rhythms of blood pressure, plasma catecholamines or levels of physical activity. It is therefore reasonable to explore the effect of meteorological variables on risk of vascular events. Any such relationship would be of potential importance as its identification could yield public health strategies intended to protect vulnerable populations.

Unfortunately, this is a complex area to study. There are many potentially important variables such as temperature, air pollution and barometric pressure. Further, fluctuation in these variables may be as relevant as the absolute level and there may be a time lag to any change in incidence dependent on the mechanism of association. The strength of the relationship need not be strong to be important. For example, in a recent study of triggers for myocardial infarction [5], cocaine use significantly in- creased the risk of myocardial infarction but is comparatively uncommon, so in population terms is less important. In this study air pollution had a small effect on risk but because we are all exposed, in population terms it may be very important [5]. Detection of such a small association will require large and adequately powered studies.

\section{Potential Biologic Mechanisms}

There are well-understood mechanisms through which changes in environmental variables could influence stroke risk. The winter months are associated with change in a number of potentially adverse physiological parameters. Serum lipid levels increase slightly, particularly in those with the highest levels of cholesterol. Similar patterns have been described in studies of blood glucose and serum fibrinogen concentration. Fibrinogen is a predictor of both ischaemic heart disease and stroke events, is highest in winter months [6]. Perhaps most notably, arterial blood pressure increases during the winter months.

Some of these winter changes may be mediated by temperature, although physical activity, exposure to sunlight and other seasonal factors likely confound. Peripheral vasoconstriction occurs in response to lower ambient temperature in attempt to divert blood flow to central organs. This increases systemic vascular resistance and causes an appreciable rise in blood pressure. In one study, blood pressure was $8 \mathrm{~mm} \mathrm{Hg}$ higher in the lowest quintile of ambient temperature $\left(<8^{\circ} \mathrm{C}\right)$ compared to the highest $\left(>21^{\circ} \mathrm{C}\right)$ [7]. Such a blood pressure change is likely to translate into an increase in both ischaemic and haemorrhagic stroke risk. Acute exposure to the cold has been found to cause increased platelet reactivity, perhaps mediated via increased levels of plasma noradrenaline, to link with lower levels of the endogenous antithrombotic protein $\mathrm{C}$ and to cause haemoconcentration [8]. Higher environmental temperatures are also associated with haemoconcentration, together with relative impairment of peripheral vascular endothelial function [9].

\section{Season and Stroke Incidence}

It is estimated that as many as 70,000 excess deaths occurred in Europe following the summer heat wave in 2003 , and those who are socially isolated, housebound or 
with pre-existing health problems are particularly vulnerable. Excess winter mortality remains a significant concern in many countries and there may be as many as 30,000 excess winter deaths in the United Kingdom [10]. Specific analyses of seasonal effects upon stroke incidence are conflicting but most have reported a seasonal peak in stroke incidence and mortality in the colder winter (and spring) months.

It is of great interest that seasonal mortality differs between countries. For example, in one study [11] the coefficient of variation for seasonal mortality was highest in Southern European countries and in Ireland, rather than in the coldest countries of Northern Europe such as Finland. The landmark Eurowinter study [12] reported similar findings, with the increase in stroke risk in Athens with lower temperature being much higher than in Helsinki. Further work from this group confirmed that cold-related death is greater with lower temperatures in warmer regions and perhaps that heat-related death is highest in colder regions. In the Eurowinter study, personal exposure factors were quantified and interestingly, at a standard temperature of $7^{\circ} \mathrm{C}$, use of heating and living-room temperatures were lowest in regions with warm winters such as Athens and Palermo, as were use of protective clothing. This raises the possibility that simple public health measures could ameliorate some of the increase in risk.

\section{Temperature and Stroke Incidence}

Many studies have investigated the possibility of a link between ambient temperature and stroke. As may be expected from the above points, it is difficult to draw clear conclusions from the existing data; biologic mechanisms could explain an increased risk of stroke at extremes of temperature and the underlying climate of the region being studied could influence any association.

The relevant data have been reviewed extensively elsewhere [13] and a discursive summary is given below. Low ambient temperature has been shown to link with increased admission rates, length of hospital stay and stroke mortality rate, particularly among the elderly [14]. A relationship between reduced temperature and ischaemic stroke has been demonstrated by groups in differing geographical regions including Korea and Siberia and in a multi national WHO Collaborative Study. The Siberian data also suggest that these findings extend to intracerebral haemorrhage.
In contrast, other large epidemiological studies conducted across Europe has demonstrated a strong association between all cause mortality and increased temperature, again particularly affecting the elderly. Risk of ischaemic stroke in the west of Scotland has been shown to increase by $2.1 \%$ with each $1{ }^{\circ} \mathrm{C}$ increase in temperature in the preceding twenty-four hours [15]. We found this increase was driven by an increase in rate of lacunar infarction [15] with rising temperature. In a further study change in temperature of more than $5^{\circ} \mathrm{C}$ has been associated with increased risk of ischaemic stroke, regardless of whether this change is positive or negative [16].

No study has yet adequately addressed potential confounding factors; physical activity, alcohol consumption and even presentation to hospital with stroke symptoms may be influenced by prevailing meterological conditions. Most importantly, the extent to which individuals were exposed to the climatic variable being studied is difficult to quantify because of factors such as air conditioning and heating systems.

\section{Atmospheric Pressure and Stoke Incidence}

The influence of atmospheric pressure on stroke incidence has been reported in a small number of studies, primarily with reference to intracerebral and subarachnoid haemorrhage. However, data are also conflicting with increased absolute levels of atmospheric pressure having been associated with increased or lower rates of both conditions The physiological mechanism for any association between atmospheric pressure and incidence of intracranial haemorrhage is unexplained. Changes in barometric pressure could lead to changes in pressure across blood vessel walls and thus predispose to rupture and bleeding complications. This remains theory and is by no means proven or directly supported by experimental animal or human data.

\section{References}

1 O’Donnell MJ, Xavier D, Liu L, et al: Risk factors for ischaemic and intracerebral haemorrhagic stroke in 22 countries (the INTERSTROKE study): a case control study. Lancet 2010;376:112-123.

-2 Manfredini R, Casetta I, Paolini E, et al: Monday preference in onset of ischaemic stroke. Am J Med 2001;111:401-403.

-3 Conway J, Boon N, Davies C, Jones JV, Sleight P: Neural and hormonal mechanisms involved in blood pressure variability. J Hypertens 1984; 2:203-208

4 Tofler GH, Muller JE: Triggering of acute cardiovascular disease and potential preventative strategies. Circulation 2006;114:1863-1872. 
$\checkmark 5$ Nawrot TS, Perez L, Kunzli N, Munters E, Nemery B: Public health importance of triggers of myocardial infarction: a comparative risk assessment. Lancet 2011;377:732-740.

6 Stout R, Crawford V: Seasonal variations in fibrinogen concentrations among elderly people. Lancet 1991;338:9-13.

7 Alperovitch A, Lacombe JM, Hanon O, et al: Relationship between blood pressure and outdoor temperature in a large sample of elderly individuals. Arch Intern Med 2009;169:75-80.

-8 Kawahara J, Sano H, Fukuzaki H, Saito K, Hirouchi H: Acute effects of exposure to cold on blood pressure, platelet function and sympathetic nervous activity in humans. Am J Hypertens 1989;2:724-726.

-9 Nawrot T, Staessen J, Fagard R, Van Bortel L, Struijker-Boudier H: Endothelial function and outdoor temperature. Eur J Epidemiol 2005;20: 407-410.

10 Aylin P, Morris S, Wakefield J, Grossinho A, Jarup L, Elliott P: Temperature, housing, deprivation and their relationship to excess winter mortality in Great Britain, 1986-1996. Int J Epidemiol 2001;35:11001108 .

11 Healy J: Excess winter mortality in Europe: a cross country analysis identifying key risk factors. J Epidemiol Community Health 2003;57: 784-789.

12 Eurowinter Group: Cold exposure and winter mortality from ischaemic heart disease, cerebrovascular disease, respiratory disease, and all causes in warm and cold regions of Europe. Lancet 1997;349:1341-1346.

-13 McArthur K, Dawson J, Walters MR: What is it with the weather and stroke? Expert Rev Neurother 2010;10:243-249.

- 14 Hong Y, Rha J, Lee J, Ha E, Kwon H, Kim H: Ischaemic stroke associated with decrease in temperature. Epidemiology 2003;14:473-478.

15 Dawson J, Weir C, Wright F, Bryden C, Aslanyan S, Lees K, et al: Associations between meteorological variables and acute stroke hospital admissions in the west of Scotland. Acta Neurol Scand 2008;117:85-89.

16 Kyobutungi C, Grau A, Stieglbauer G, Becher H: Absolute temperature, temperature change and stroke risk: a case crossover study. Eur J Epidemiol 2005;20:693-698.

Jesse Dawson

College of Medicine, Veterinary and Life Sciences Institute of Cardiovascular and Medical Sciences

Western Infirmary, Dumbarton Road, Glasgow G11 6NT (UK) Tel. +44 141211 6395, E-Mail jesse.dawson@glasgow.ac.uk

\section{2 \\ Outdoor Air Pollution and Stroke: An Overview}

\section{R. Maheswaran, T. Pearson}

Public Health GIS Unit, School of Health and Related

Research, University of Sheffield, Sheffield, UK

Air pollution is defined as any undesirable modification of air by substances that are toxic or may have adverse effects on health or that are offensive though not necessarily harmful to health [1]. Pollutants may be solids, liquids or gases and are derived from a number of sources which can be broadly classified as outdoor, indoor and occupational. Pollutants that have been exam- ined include particulate matter (PM), nitrogen dioxide $\left(\mathrm{NO}_{2}\right)$, sulphur dioxide $\left(\mathrm{SO}_{2}\right)$, carbon monoxide and ozone. In this article, only outdoor air pollution is considered.

There are numerous sources of outdoor air pollution. In the United Kingdom, industry and road transport are currently the main contributors. Government estimates attribute $46 \%$ of $\mathrm{NO}_{2}$ and $26 \%$ of $\mathrm{PM}_{10}$ to industry and $30 \%$ of $\mathrm{NO}_{2}$ and $18 \%$ of $\mathrm{PM}_{10}$ to road transport [2]. Domestic combustion and agriculture are also significant contributors. In low- and middle-income countries, biomass and solid fuels are major sources but road transport and industry are making increasingly significant contributions. In several western countries, there has been a substantial fall in pollution levels over time. In the United Kingdom, black smoke concentrations were around 150 $\mu \mathrm{g} / \mathrm{m}^{3}$ in the early $1960 \mathrm{~s}$ but declined to $20 \mu \mathrm{g} / \mathrm{m}^{3}$ by 1990. In London, $\mathrm{PM}_{10}$ and $\mathrm{NO}_{2}$ levels decreased in the 1990s but have remained relatively unchanged over the last decade.

The health effects of outdoor air pollutants on stroke may be investigated using a number of epidemiological study designs. These include cohort, case-control, ecological correlation, time series and case-crossover studies, studies of pollution episodes and studies assessing the effects of policy interventions. Panel studies may be used to examine potential mechanisms mediating the link, such as blood pressure variability and changes in blood coagulability in relation to fluctuations in pollution concentrations.

Early reports of the association between air pollution and stroke come from studies investigating the health effects of severe pollution episodes, which were often associated with temperature inversions. The London smog episode in December 1952 is the classic example of a severe pollution episode. Smoke concentrations increased from around $300 \mu \mathrm{g} / \mathrm{m}^{3}$ to around $2,500 \mu \mathrm{g} / \mathrm{m}^{3}$ and were accompanied by large increases in $\mathrm{SO}_{2}$ and other pollutants resulting in a toxic acidic atmosphere. The pollution episode lasted 5 days. Stroke mortality during the pollution week compared with the previous week was 1.25 (95\% CI, 1.03-1.47) [3], but daily applications for hospital admission for cerebral haemorrhage did not increase [4]. In a pollution episode in New York in 1966, stroke mortality during the episode compared with a control period was 1.24 (1.04-1.44) [5]. It is interesting to note that whilst increases in pollution concentrations during these pollution episodes were very large, there was only a modest increase in stroke mortality and no evidence of an increase in cerebral haemorrhage. 
Daily time series data have been used in several studies examining the acute effects of outdoor air pollution. Time series analyses and case-crossover study designs were used to examine associations. Several studies examined mortality whilst others used hospital admissions as a proxy for incident cases. A few studies have also used case registers which aim to capture all incident cases in a defined population. In terms of findings, several acute effect studies reported associations between various outdoor air pollutants and ischaemic stroke, whilst others reported associations with haemorrhagic stroke. However, a number of studies also found no significant evidence of association.

In terms of chronic exposure, there are few studies specifically examining stroke. The studies have used cohort, case-control and ecological study designs. Whilst there is some evidence linking air pollution and stroke from these studies, the evidence is mixed. Of the five cohort studies identified, two found significant evidence of association whilst a case-control study found no significant association. With regard to ecological studies, we have previously found that stroke mortality increases with proximity to main roads, with the latter used as a proxy indicator for road traffic related pollution [6]. We found the risks to be 1.07 (1.04-1.09) and 1.04 (1.02-1.06) amongst men and women living within $200 \mathrm{~m}$ of a main road compared with those living $1 \mathrm{~km}$ or more away from a main road. In a further study using modelled pollutants, we found that the highest $\mathrm{NO}_{\mathrm{x}}$ category by quintile was associated with a $1.37(1.19-1.57)$ relative risk for stroke mortality and a $1.13(1.01-1.27)$ relative risk for stroke admissions compared with the lowest exposure category [7].

Studies examining stroke mortality, however, are unable to distinguish between the effects of an exposure on incidence of stroke and effects of the exposure on survival after stroke. We examined the effect of outdoor air pollution on survival after stroke in a population-based cohort study using the South London Stoke Register [8]. The register was set up to capture all cases of first-ever stroke occurring amongst the resident population living in a defined geographical area. High resolution modelled air pollution concentrations were linked to patients in the stroke cohort. A $10-\mu \mathrm{g} / \mathrm{m}^{3}$ increase in $\mathrm{NO}_{2}$ concentration was associated with a hazard ratio of 1.28 (1.11-1.48) whilst a $10-\mu \mathrm{g} / \mathrm{m}^{3}$ increase in $\mathrm{PM}_{10}$ concentration was associated with a hazard ratio of $1.52(1.06-2.18)$. A reduction in exposure to $\mathrm{NO}_{2}$ of $10 \mu \mathrm{g} / \mathrm{m}^{3}$ was estimated to be associated with a $22 \%$ reduction in risk of death after stroke, a magnitude similar to that achieved by stroke

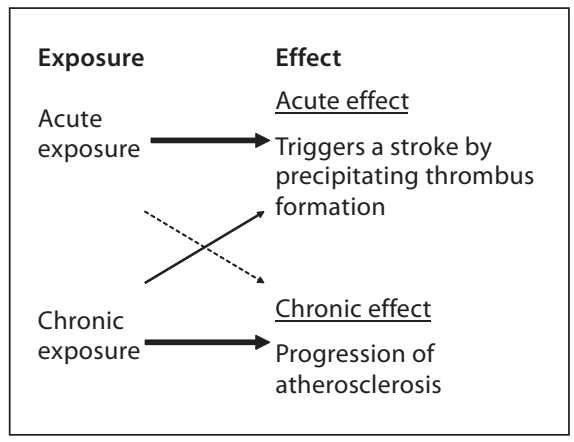

Fig. 1. A conceptual framework linking air pollution exposure and stroke.

units. In a recent ecological study examining stroke incidence, we found evidence of an increase in ischaemic but not haemorrhagic stroke incidence amongst older people [9]. A $10-\mu \mathrm{g} / \mathrm{m}^{3}$ increase in $\mathrm{PM}_{10}$ concentration was associated with a relative risk of $1.86(1.10-3.13)$ for ischaemic stroke amongst people aged $65-79$ years.

When considering potential mechanisms by which air pollution could cause stroke, it is useful to have a conceptual framework incorporating the dimensions of exposure and effect. This is shown in figure 1. Whilst studies typically use the terms 'acute effects' and 'chronic exposure', it is worth considering the corollaries 'chronic effects' and 'acute exposure' in a theoretical conceptual framework. An acute exposure is a transient or shortterm increase in exposure, perhaps lasting a few hours to some days. This would include daily variation in pollution levels which spike on some days and pollution episodes during which pollution levels remain high for a number of consecutive days. Acute exposure may result in an acute effect such as plaque rupture and thrombosis triggering a stroke. Acute exposures are examined for association with acute effects in time series and case-crossover studies and studies of pollution episodes. In theory, an acute exposure might also initiate some mechanism which causes or accelerates a chronic effect, in this case progression of atherosclerosis. This would be analogous to a single radiation exposure initiating a cancerous process. However, there is currently no epidemiological or experimental evidence specifically showing a link between a single acute exposure to air pollution and progression of atherosclerosis.

Chronic exposure may be regarded as exposure to high levels of pollution on a long-term basis. Chronic exposure, that is average exposure experienced by people living in polluted areas, is usually investigated for association with 
stroke incidence or mortality using cohort, case-control and ecological studies. However, long-term average exposure values cannot distinguish between an area having continuously high levels of pollutants and an area having numerous spikes of high pollution resulting in a high average value. The increased risk of stroke associated with chronic exposure could in effect be due to acute exposure spikes triggering strokes amongst the population living in a high pollution area. The influence of chronic exposure on a chronic effect, such as progression of atherosclerosis, would be identified by studies examining atherosclerosis as the outcome. Even in this case, it could be argued that there are two scenarios - chronically high (steady) exposure levels causing progression of atherosclerosis, and repeated acute exposure (numerous spikes) resulting in progression of atherosclerosis. Animal experiments in which the pattern of exposure could be controlled would be able to distinguish between the two scenarios, but epidemiological studies might struggle to do so.

There is increasing evidence for various potential mechanisms, mainly in relation to particulate air pollution [10]. Exposure to particulate air pollution may cause lung injury and trigger an inflammation-related cascade. High air pollution concentrations have been found to be associated with increased plasma viscosity and decreased prothrombin time. Chronic exposure to particulate air pollution has been found to cause progression of atherosclerosis in animal studies and has been linked to increased carotid intima-media thickness and coronary artery calcification. There is also some evidence of increase in blood pressure associated with particulate exposure.

In terms of research and policy, whilst there is increasing evidence regarding the link between outdoor air pollution exposure and stroke, further studies are needed to confirm the link and quantify the magnitude of the association. These studies could use improved exposure assessment methods and examine stroke subtypes. Policy relevant research would include identifying policy interventions that have an impact on air quality and evaluating their impact on stroke risk.

\section{References}

1 Last JM: A Dictionary of Epidemiology. Oxford, Oxford University Press, 1995

2 House of Commons Environmental Audit Committee: Air Quality Fifth Report of Session 2009-10. http://www.publications.parliament. uk/pa/cm200910/cmselect/cmenvaud/229/229i.pdf

3 Logan WPD: Mortality in the London fog incident, 1952. Lancet 1953;i:336-338.

4 Abercrombie GF: December fog in London and the emergency bed service. Lancet 1953;i:234-235.
5 Glasser M, Greenburg L, Field F: Mortality and morbidity during a period of high levels of air pollution. Arch Environ Health 1967;15:684694.

-6 Maheswaran R, Pearson T, Smeeton NC, Beevers SD, Campbell MJ, Wolfe CD: Impact of outdoor air pollution on survival after stroke: population-based cohort study. Stroke 2010;41:869-877.

$\checkmark 7$ Maheswaran R, Haining RP, Brindley P, Law J, Pearson T, Fryers PR, Wise S, Campbell MJ: Outdoor air pollution and stroke in Sheffield, United Kingdom - a small-area level geographical study. Stroke 2005; 36:239-243.

8 Maheswaran R, Elliott P: Stroke mortality associated with living near main roads in England and Wales - a geographical study. Stroke 2003; 34:2776-2780.

9 Maheswaran R, Pearson T, Smeeton NC, Beevers SD, Campbell MJ, Wolfe CD: Outdoor air pollution and incidence of ischemic and hemorrhagic stroke - a small area level ecological study. Stroke 2011; in press.

10 Brook RD, Rajagopalan S: Particulate matter air pollution and atherosclerosis. Curr Atheroscler Rep 2010;12:291-300.

Dr. R. Maheswaran

Public Health GIS Unit

School of Health and Related Research, University of Sheffield Regent Court, 30 Regent Street, Sheffield S1 4DA (UK)

Tel. +44 114222 0681, E-Mail r.maheswaran@sheffield.ac.uk

\section{3 The Influence of Ozone Pollution on Stroke Epidemiology}

Y. Béjot, M. Giroud, J.-B. Henrotin

Stroke Registry of Dijon (Inserm et Institut de Veille Sanitaire), EA4184, University Hospital and Medical

School of Dijon, University of Burgundy, Dijon, France

Atmospheric pollution is considered a major environmental health issue. Ozone is the main component of photochemical pollution, but whereas the short-term effects of ozone pollution on both respiratory health and mortality are well documented [1], less is known about its impact on cerebrovascular diseases.

In this article, we aimed to review the epidemiological aspects of the association between ozone pollution and stroke, the different factors that explain the conflicting results of studies that addressed this topic, and the pathophysiological mechanisms potentially involved.

\section{What Is Ozone Pollution?}

Ozone $\left(\mathrm{O}_{3}\right)$ is found naturally in the stratosphere, a layer of the Earth's upper atmosphere, and stratospheric ozone has been called 'good' ozone because it protects the Earth's surface from dangerous ultraviolet light. Ozone 


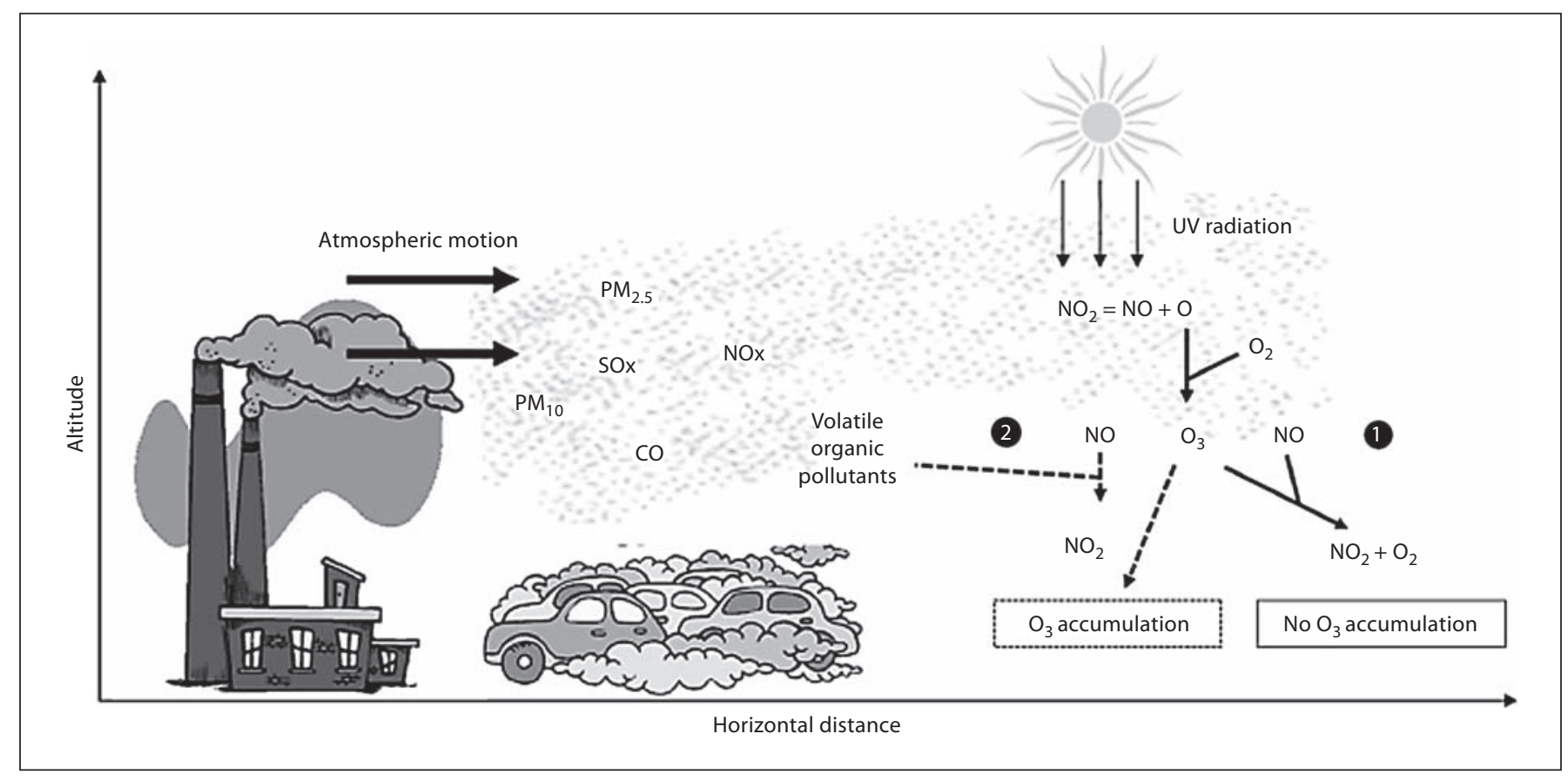

Fig. 1. Schematic representation of the atmospheric chemistry involved in ozone formation. Ultraviolet (UV) radiation from the sun breaks down nitrogen dioxide $\left(\mathrm{NO}_{2}\right)$ into nitric oxide $(\mathrm{NO})$ and atomic oxygen $(\mathrm{O})$. Oxygen atoms combine with oxygen molecules $\left(\mathrm{O}_{2}\right)$ to form ozone $\left(\mathrm{O}_{3}\right)$. However, under normal conditions, ozone will not accumulate when NO is present, as the two molecules react to reform $\mathrm{NO}_{2}$ and $\mathrm{O}_{2}$ (1). Problems occur when volatile organic pollutants from vehicle exhaust and industrial emissions react in the atmosphere to form oxygenated products such as aldehydes. The oxygen in these molecules allows NO to form $\mathrm{NO}_{2}$, without breaking down ozone, thus ozone accumulates (2). can also be found in the troposphere, the lowest layer of the atmosphere. Tropospheric ozone is often termed 'bad' ozone. The atmospheric chemistry involved in ozone formation is complex (fig. 1) and ozone is considered a secondary pollutant since its buildup depends upon the relative concentrations of nitrogen oxides, hydrocarbons and other pollutants, and sunlight. Ozone may be transported by the wind over distances of 400-500 km a day. Consequently, ozone pollution may eventually be found in suburban and rural areas far away from the sources of the pollutants. Another particularity is that ozone production fluctuates both during the year, with a higher production in summertime in regions with high emissions from traffic and industry, and during the day, with a peak in the afternoon because of the involvement of sunlight.

In order to fight against ozone pollution, the European Commission published a directive on 'ozone in ambient air' in 2002 [2]. The directive requires national authorities to inform the public about any incidence of ozone pollution above $180 \mu \mathrm{g} / \mathrm{m}^{3}$ (information threshold) and defines a long-term objective to limit the number of days with average ozone concentrations above $120 \mu \mathrm{g} / \mathrm{m}^{3}$ to less than 25 per year. Member states should report monthly to the European Commission on all exceedances of the information thresholds. Each year they must provide additional information on ozone pollution, especially concerning exceedances of the long-term objective. In the summer of 2005 exceedances of the information threshold were observed mainly in northern Italy, southern France, Greece and Portugal. However, an improvement in ozone levels was observed over time. Hence, In the summer of 2009, the percentage of ozone monitoring stations reporting exceedances of the information threshold was the lowest since comprehensive reporting of Europewide data commenced in 1997 [3]. The geographical areas concerned by the exceedance of the information threshold were much smaller than in previous years. Nevertheless, as in all previous years, exceedances of the long-term objective for the protection of human health were observed in every country, in every summer month and at most stations in the summer of 2009. Approximately $84 \%$ of all stations reported one or more exceedances [3]. 


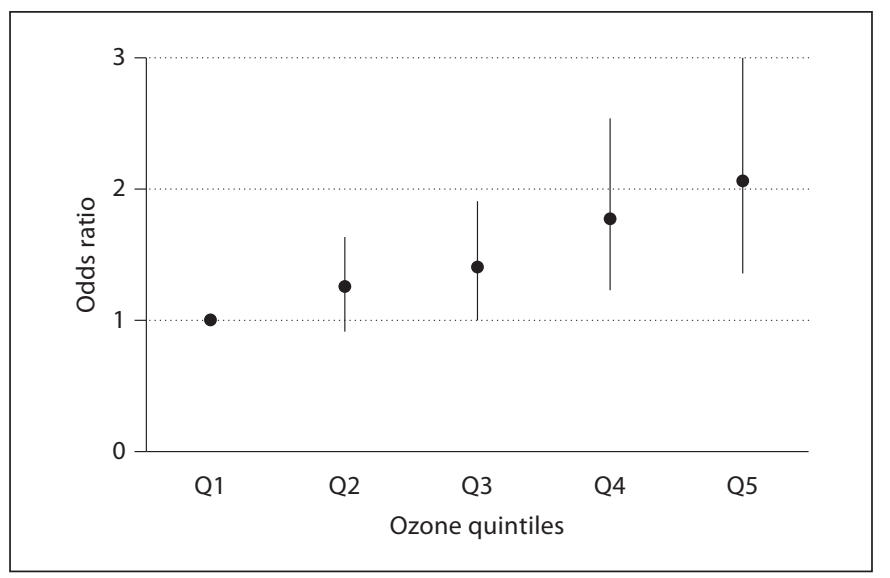

Fig. 2. Dose-response relationship between ozone quintiles (with 1-day lag) and ischemic stroke occurrence in men. Data from the Dijon Stroke Registry, France [4]. Q1: $<9 \mu \mathrm{g} / \mathrm{m}^{3}, \mathrm{Q} 2: 9-20 \mu \mathrm{g} / \mathrm{m}^{3}$, Q3: $21-32 \mu \mathrm{g} / \mathrm{m}^{3}$, Q4: $33-48 \mu \mathrm{g} / \mathrm{m}^{3}$, Q5: $>48 \mu \mathrm{g} / \mathrm{m}^{3}$.

\section{Ozone Pollution and Stroke}

Several studies have investigated the association between ozone pollution and the occurrence of stroke with sometimes conflicting results [4-10]. From the population-based stroke registry of Dijon, France, using a casecrossover design, we found a significant association between the occurrence of ischemic stroke and ozone levels with a 1-day lag, independently of other pollutants and meteorological conditions [4]. In subgroup analyses, this result was confirmed for ischemic strokes in men whereas in women, the strength of the association was weaker, and no significant association was found for hemorrhagic stroke. Of note, according to ischemic stroke subtypes, the association was observed for ischemic strokes from atheroma of large arteries and for transient ischemic attack (TIA). Moreover, the association was a linear exposureresponse relationship (fig. 2), and was stronger in the subgroup of men with at least one cardiovascular risk factor than in the subgroup of men with no risk factors. Other studies found consistent results. In the study conducted in Taipei, Taiwan, where ozone pollution was almost 3 times that observed in Dijon, ozone with a 0-day lag was significantly associated with admissions for cerebrovascular diseases in patients $>50$ years [5]. In Nueces County, Tex., USA, Lisabeth et al. [6] demonstrated borderline significant associations between same-day and previous-day ozone exposure and the risk of stroke or TIA.

Some studies investigated the effects of ozone pollution on acute stroke mortality. For example, in Seoul, Ko- rea, a significant increase of $2.9 \%$ in stroke mortality was observed for each interquartile range increase in ozone concentration on the same day [7]. Nevertheless, with mortality indicators like those used in this study, we do not know whether air pollution was a causative factor of stroke or only a precipitating factor of death after stroke, because the data were analyzed according to the date of death rather than that of stroke onset.

Contrasting with these positive results, several studies conducted in various areas around the world failed to demonstrate any significant association between ozone levels and either admissions for cerebrovascular disease or cerebrovascular disease mortality, which raises questions about the reasons for such discrepancies [8-10].

\section{Understanding the Reasons for Conflicting Results of Studies}

Several factors could account for the contrasting results of studies focusing on the influence of ozone on stroke epidemiology.

First, differences in the case-mix of the population such as demographic features including age or sex are of importance. In addition, the distribution of vascular risk factors in studied populations is certainly important in interpreting the results since the dose-response relationship between ozone exposure and stroke seems to increase concomitantly with the number of risk factors.

Secondly, differences in the assessment of ozone exposure may also account for the conflicting results. This includes technical features such as the number of monitoring stations, the mean distance between homes and the monitoring station. Moreover, the baseline levels of ozone are also essential, as the relationship between stroke and ozone pollution seems to correlate with ozone levels. Since ozone is influenced by meteorological features, local climatic conditions must be taken into consideration. In contrast, it is more difficult to control individual exposure to ozone pollution, which could affect the results. Indeed, the risk of ozone-induced stroke depends on numerous factors including time spent indoors, the use of air conditioning, as well as mobility around the home. Finally the confounding effect of other pollutants must be considered, and this largely depends on the composition of the air pollution, which varies widely from one area to another.

Thirdly, methodological issues are also of major importance. These include the procedures for case ascertainment (hospital- or population-based, exhaustive- 
ness, misclassification of time of event onset results), the study design (case crossover, time series study), and the outcome evaluated (incidence, hospital admission, mortality ...).

\section{Pathophysiological Mechanisms That Support the Association between Ozone Pollution and Stroke}

The pathophysiological mechanisms that suggest pathways linking ozone pollution and cerebrovascular diseases are certainly complex and not fully understood. Both animal and human experimental and observational studies have suggested that ozone pollution contributes to oxidative stress and is associated with increased systemic inflammatory responses, as demonstrated by the increase in blood levels of several markers including Creactive protein, interleukin 6 , and tumor necrosis factor$\alpha$. These phenomena contribute to atherosclerotic plaque instability, alterations in endothelial function, cardiac troubles such as arrhythmias, and increased coagulation and thrombosis. All together these reactions may foster the occurrence of cerebrovascular diseases by distinct pathways. However, further studies are required for better understanding of this process.

Ozone pollution may contribute to an increase in the risk of ischemic stroke, in terms of both incidence and mortality, even at low levels of exposure although a doseresponse relationship has been observed, and particularly in people with multiple vascular risk factors. Various differences between epidemiological studies make it difficult to clarify this relationship and may explain the conflicting results. The pathophysiological mechanisms and clinical implications of these findings need to be investigated more thoroughly.

\section{References}

1 Brunekreef B, Holgate ST: Air pollution and health. Lancet 2002;360: 1233-1242.

2 Directive 2002/3/EC of the European Parliament and of the Council of 12 February 2002 relating to ozone in ambient air. Official Journal of the European Communities 2002;L67:14-30.

3 European Environment Agency: Air pollution by ozone across Europe during summer 2009. Overview of exceedances of EC ozone threshold values for April-September 2009. DOI 10.2800/39256.

-4 Henrotin JB, Besancenot JP, Bejot Y, Giroud M: Short-term effects of ozone air pollution on ischaemic stroke occurrence: a case-crossover analysis from a 10-year population-based study in Dijon, France. Occup Environ Med 2007;64:439-445.

5 Chan CC, Chuang KJ, Chien LC, Chen WJ, Chang WT: Urban air pollution and emergency admissions for cerebrovascular diseases in Taipei, Taiwan. Eur Heart J 2006;27:1238-1244.
-6 Lisabeth LD, Escobar JD, Dvonch JT, Sánchez BN, Majersik JJ, Brown DL, Smith MA, Morgenstern LB: Ambient air pollution and risk for ischemic stroke and transient ischemic attack. Ann Neurol 2008;64: 53-59.

7 Hong YC, Lee JT, Kim H, Ha EH, Schwartz J, Christiani DC: Effects of air pollutants on acute stroke mortality. Environ Health Perspect 2002; 110:187-191.

8 Tsai SS, Goggins WB, Chiu HF, Yang CY: Evidence for an association between air pollution and daily stroke admissions in Kaohsiung, Taiwan. Stroke 2003;34:2612-2616.

\9 Oudin A, Strömberg U, Jakobsson K, Stroh E, Björk J: Estimation of short-term effects of air pollution on stroke hospital admissions in southern Sweden. Neuroepidemiology 2010;34:131-142.

10 Ballester F, Tenias JM, Perez-Hoyos S: Air pollution and emergency hospital admissions for cardiovascular diseases in Valencia, Spain. J Epidemiol Community Health 2001;55:57-65.

Dr. Yannick Bejot

Dijon Stroke Registry, Service de Neurologie CHU

3, rue du Faubourg Raines

FR-21000 Dijon (France)

Tel. +33 3802937 53, E-Mail ybejot@yahoo.fr

\section{Neighborhoods and Stroke}

L.D. Lisabeth

Department of Epidemiology, University of Michigan,

Ann Arbor, Mich., USA

There has been recent interest in how residential environments affect health with the notion that the environment in which one lives may provide information about conditions related to health not captured by individual-level variables. Neighborhoods have emerged as a relevant context given the plausible pathways by which features of the physical and social environment of a neighborhood may influence health and, in particular, cardiovascular diseases (fig. 1). There is also an interest in the health disparities research community to understand how residential environments may explain poorer health outcomes among race-ethnic minority groups and the poor. Finally, the last decade has seen the application of new analytic techniques, including multilevel modeling, which allows researchers to quantify the impact of both individual-level and contextual variables, such as neighborhood features, on health outcomes greatly advancing research in this area. See Diez Roux and Mair for a review [1].

While there has been an explosion of literature considering the potential health impacts of neighborhood environments in the broader cardiovascular realm, with a particular focus on obesity, research considering stroke 
Fig. 1. Schematic representation of possible pathways linking residential environments to cardiovascular risk. With permission from Diez Roux [2].

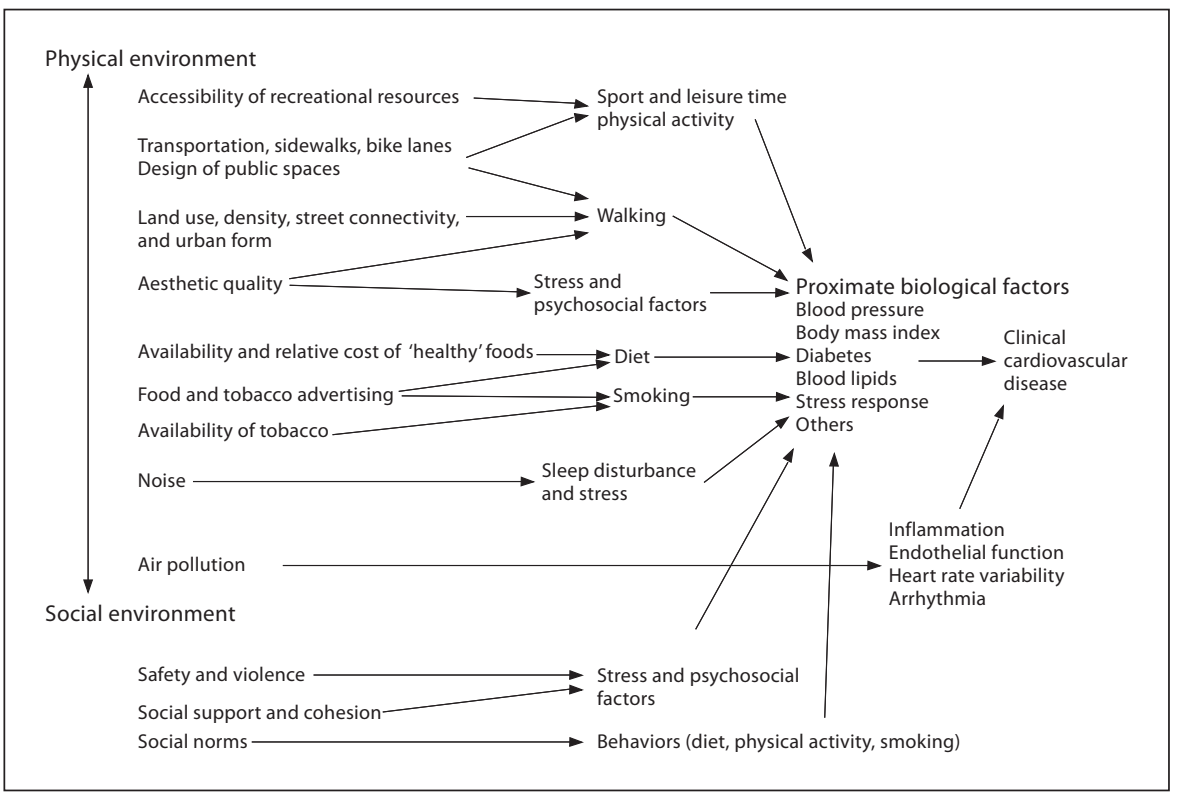

specifically is sparse. This is surprising given that the pathways by which neighborhoods influence stroke are likely similar to those for heart disease because of shared downstream risk factors such as hypertension, diabetes and smoking (fig. 1) [2]. Evident from figure 1, there are many neighborhood exposures that are reasonable candidates for exploration in stroke. Given its early stage, the limited research on neighborhoods and stroke has primarily relied on existing data sources, such as census data, to measure area-level socioeconomic status (SES, for example, median household income for an area) as a proxy for more specific features of the physical and social environment that may influence stroke.

There have been studies considering the association between incident stroke as well as stroke outcomes, primarily stroke mortality. Given space limitations, the focus of this brief review is on the studies considering incident stroke. There have been approximately a dozen studies that have considered the association between neighborhood SES, or specific features of the neighborhood, and stroke, with the majority from Europe. These studies have varied in the populations studied, study designs used, definition of neighborhood, measures of neighborhood SES, and level adjustment for individuallevel confounders making comparisons across studies challenging. These studies fall broadly into two categories: (1) ecologic studies and (2) observational studies including case-control and cohort studies. A summary of findings is briefly outlined below.

\section{Ecologic Studies}

The majority of studies have been ecologic comparing area-level measures of SES with stroke rates or counts of stroke in the same area [3-10]. These ecologic studies have overwhelmingly focused on the use of available data sources for measuring neighborhood SES, although the specific measure(s) of SES and the level at which they were measured have varied across studies (table 1). As an example, Grimaud et al. [4] recently published the results of a study of the association of neighborhood SES and stroke risk in the Dijon Stroke Registry. The authors considered ten different census measures of SES and found that six of the SES indicators, including percent of the population aged 60 or older, percent of the population non-French nationals, unemployment, percent renters, percent without a car and income inequality, were associated with stroke risk after age and sex adjustment. Similarly, the other ecologic studies, which were conducted in various communities in the US, Europe and Australia, have suggested that increasing neighborhood disadvantage is associated with increasing stroke risk either broadly or within certain subgroups of the population such as younger individuals.

Results of these ecologic studies raise the hypothesis that neighborhood disadvantage, either broadly or as it relates to specific features of the neighborhood, is associated with stroke risk. There are, however, a number of issues with this research that do not allow definitive con- 
Table 1. Ecologic studies of neighborhood disadvantage and stroke risk

\begin{tabular}{|c|c|c|c|c|c|c|c|c|}
\hline Author & Study & $\begin{array}{l}\text { Study } \\
\text { popula- } \\
\text { tion }\end{array}$ & $\begin{array}{l}\text { Time } \\
\text { period }\end{array}$ & $\begin{array}{l}\text { Neighborhood } \\
\text { measure(s) }\end{array}$ & $\begin{array}{l}\text { Stroke } \\
\text { endpoint }\end{array}$ & $\begin{array}{l}\text { Geo- } \\
\text { graphic } \\
\text { level }\end{array}$ & $\begin{array}{l}\text { Con- } \\
\text { founders } \\
\text { considered }\end{array}$ & Result \\
\hline $\begin{array}{l}\text { Grimaud } \\
\text { et al. [4] }\end{array}$ & $\begin{array}{l}\text { Dijon Stroke } \\
\text { Registry }\end{array}$ & $\begin{array}{l}\text { indi- } \\
\text { viduals } \\
\geq 40 \text { years }\end{array}$ & $1995-2003$ & $\begin{array}{l}\% \text { population }>60 \text {, } \\
\% \text { non-French nationals, } \\
\% \text { 1-parent families, } \\
\% \text { adults without } \\
\text { secondary education, } \\
\% \text { manual worker, } \\
\% \text { renting, \% without car, } \\
\text { unemployment, median } \\
\text { household income, } \\
\text { income inequality }\end{array}$ & $\begin{array}{l}\text { ischemic } \\
\text { stroke, } \\
\text { ICH, SAH }\end{array}$ & IRIS & age, gender & $\begin{array}{l}\text { associated with stroke } \% \\
\text { population }>60(\mathrm{RR}=0.79 ; \\
\mathrm{p}=0.004), \% \text { non-French } \\
\text { nationals }(\mathrm{RR}=1.12 ; \mathrm{p}=0.05) \\
\% \text { renting }(\mathrm{RR}=1.21 ; \\
\mathrm{p}=0.02), \% \text { without car } \\
(\mathrm{RR}=1.21 ; \mathrm{p}=0.05), \% \\
\text { unemployment }(\mathrm{RR}=1.16 ; \\
\mathrm{p}=0.02), \text { income inequality } \\
(\mathrm{RR}=1.23 ; \mathrm{p}=0.003)\end{array}$ \\
\hline $\begin{array}{l}\text { Lisabeth } \\
\text { et al. [6] }\end{array}$ & $\begin{array}{l}\text { Brain Attack Sur- } \\
\text { veillance in Corpus } \\
\text { Christi Project }\end{array}$ & $\begin{array}{l}\text { indi- } \\
\text { viduals } \\
\geq 45 \text { years }\end{array}$ & $2000-2003$ & disadvantage score & $\begin{array}{l}\text { ischemic } \\
\text { stroke }\end{array}$ & $\begin{array}{l}\text { census } \\
\text { tract }\end{array}$ & $\begin{array}{l}\text { age, gender, } \\
\text { ethnicity }\end{array}$ & $\begin{array}{l}\text { disadvantage score associated } \\
\text { with stroke }(\mathrm{RR}=0.79 \\
95 \% \text { CI: } 0.63-1.00)\end{array}$ \\
\hline $\begin{array}{l}\text { Kleindorfer } \\
\text { et al. [5] }\end{array}$ & $\begin{array}{l}\text { Greater Cincinnati/ } \\
\text { Northern Kentucky } \\
\text { Stroke Study }\end{array}$ & $\begin{array}{l}\text { all indi- } \\
\text { viduals }\end{array}$ & 1999 & $\begin{array}{l}\% \text { population below } \\
\text { poverty }\end{array}$ & $\begin{array}{l}\text { ischemic } \\
\text { stroke, } \\
\text { ICH, SAH }\end{array}$ & $\begin{array}{l}\text { census } \\
\text { tract }\end{array}$ & $\begin{array}{l}\text { age, gender, } \\
\text { race }\end{array}$ & $\begin{array}{l}\text { \% below poverty associated } \\
\text { with stroke }(\mathrm{p}=0.003)\end{array}$ \\
\hline $\begin{array}{l}\text { Thrift } \\
\text { et al. [9] }\end{array}$ & $\begin{array}{l}\text { Northeast } \\
\text { Melbourne Stroke } \\
\text { Incidence Study }\end{array}$ & $\begin{array}{l}\text { all indi- } \\
\text { viduals }\end{array}$ & 1997-1999 & $\begin{array}{l}\text { disadvantage category } \\
\text { based on index of relative } \\
\text { socioeconomic } \\
\text { disadvantage }\end{array}$ & $\begin{array}{l}\text { ischemic } \\
\text { stroke, } \\
\text { ICH, SAH }\end{array}$ & $\begin{array}{l}\text { postal } \\
\text { codes }\end{array}$ & age & $\begin{array}{l}\text { disadvantage category } \\
\text { associated with stroke } \\
(\mathrm{p}<0.0001)\end{array}$ \\
\hline $\begin{array}{l}\text { Macleod } \\
\text { and } \\
\text { Andrews [10] }\end{array}$ & $\begin{array}{l}\text { Scottish hospital } \\
\text { discharge data }\end{array}$ & $\begin{array}{l}\text { indi- } \\
\text { viduals } \\
>15 \text { years }\end{array}$ & 1995-1999 & $\begin{array}{l}\text { deprivation category } \\
\text { based on Carstairs index }\end{array}$ & $\begin{array}{l}\text { ischemic } \\
\text { stroke, } \\
\text { ICH, SAH }\end{array}$ & $\begin{array}{l}\text { postal } \\
\text { codes }\end{array}$ & age, gender & $\begin{array}{l}\text { deprivation category associated } \\
\text { with stroke and SAH } \\
\text { admission }(\mathrm{p}<0.00001)\end{array}$ \\
\hline $\begin{array}{l}\text { Smits } \\
\text { et al. [7] }\end{array}$ & $\begin{array}{l}\text { Netherlands study } \\
\text { on quality of stroke } \\
\text { care }\end{array}$ & $\begin{array}{l}\text { all indi- } \\
\text { viduals }\end{array}$ & 1991-1992 & $\begin{array}{l}\text { average income } \\
\text { (measured by telephone } \\
\text { interview with residents) }\end{array}$ & $\begin{array}{l}\text { ischemic } \\
\text { stroke, } \\
\text { ICH }\end{array}$ & $\begin{array}{l}\text { postal } \\
\text { codes }\end{array}$ & $\begin{array}{l}\text { family phase, } \\
\text { urbanization, } \\
\text { province }\end{array}$ & $\begin{array}{l}\text { below-average income } \\
\text { associated with stroke } \\
(\mathrm{RR}=1.27 ; 95 \% \mathrm{CI}: 1.08-1.51) \\
\text { compared with average or } \\
\text { above-average income }\end{array}$ \\
\hline $\begin{array}{l}\text { Engstrom } \\
\text { et al. [3] }\end{array}$ & $\begin{array}{l}\text { Stroke Register in } \\
\text { Malmo, Sweden }\end{array}$ & $\begin{array}{l}\text { indi- } \\
\text { viduals } \\
50-79 \\
\text { years }\end{array}$ & 1989-1998 & disadvantage score & $\begin{array}{l}\text { ischemic } \\
\text { stroke, } \\
\text { ICH, SAH }\end{array}$ & $\begin{array}{l}\text { adminis- } \\
\text { trative } \\
\text { areas }\end{array}$ & age, gender & $\begin{array}{l}\text { disadvantage score associated } \\
\text { with stroke }(\mathrm{r}=-0.62, \mathrm{p}= \\
0.008) \text { for men and }(\mathrm{r}=-0.67 \\
\mathrm{p}=0.004) \text { for women }\end{array}$ \\
\hline $\begin{array}{l}\text { Starr } \\
\text { et al. [8] }\end{array}$ & $\begin{array}{l}\text { Scottish Heart } \\
\text { Health Study/ } \\
\text { hospital discharge } \\
\text { data }\end{array}$ & $\begin{array}{l}\text { indi- } \\
\text { viduals } \\
40-64 \\
\text { years }\end{array}$ & 1984-1986 & $\begin{array}{l}\text { deprivation score based } \\
\text { on Carstairs index }\end{array}$ & $\begin{array}{l}\text { ischemic } \\
\text { stroke, } \\
\text { ICH, SAH }\end{array}$ & $\begin{array}{l}\text { govern- } \\
\text { ment } \\
\text { districts }\end{array}$ & $\begin{array}{l}\text { population } \\
\text { density, } \\
\text { smoking, } \\
\text { SBP, BMI }\end{array}$ & $\begin{array}{l}\text { deprivation score associated } \\
\text { with stroke admission } \\
(b=0.83, p<0.0001) \text { in men }\end{array}$ \\
\hline
\end{tabular}

$\mathrm{ICH}=$ Intracerebral hemorrhage; $\mathrm{SAH}=$ subarachnoid hemorrhage; $\mathrm{RR}=$ relative risk; $\mathrm{BMI}=$ body mass index; $\mathrm{SBP}=$ systolic blood pressure.

clusions. First, given the ecologic design (i.e. group-level analysis), there has been limited adjustment for individual-level variables that may be important confounders. It is unclear from these studies if it is truly aspects of the neighborhood that are playing a role or whether such associations emerge due to the social patterning of stroke risk factors with socioeconomic disadvantage. Of note, if risk factors, such as hypertension, are on the causal pathway between neighborhood environments and stroke then adjustment for these factors may not be warranted.
There are also important issues to consider related to selection. Notably, all of these studies have been cross-sectional. Individuals who are in poor health may move to areas with greater disadvantage, thus, the observed associations might reflect these selection processes versus a causal association. Finally, given the reliance on available data to measure neighborhood exposures, most of these studies do not speak to the specific features of the neighborhood that may be important for stroke. Of note, one recent ecologic study focused on a specific neighborhood 
aspect, density of fast food restaurants, and stroke risk. The authors found that stroke risk in a neighborhood increased by $1 \%$ for every fast food restaurant $(R R=1.01$; 95\% CI: 1.00-1.01) [11]. Like the other studies mentioned, this study was ecologic and subject to the same limitations. Many of these limitations can be overcome with other study designs.

\section{Case-Control and Cohort Studies}

There have been a handful of case-control and cohort studies considering the connection between neighborhoods and stroke. These studies compare area SES among stroke cases and controls or compare stroke risk among those exposed to varying levels of area SES accounting for individual-level variables that are possible confounders, a strength of these designs compared with the ecologic work. Cohort studies are also not subject to the selection issues noted above as people are entered into the study when they are disease-free. In the existing case-control and cohort studies the area-level measures of SES were primarily but not solely based on existing data sources. Hart et al. [12] considered the association between neighborhood disadvantage as measured by the Carstairs index and risk of stroke in two separate cohort studies conducted in Scotland. In the first, area SES showed a borderline association with stroke risk in men, but this association was attenuated and no longer significant after adjustment for age and stroke risk factors [12]. Results were similar in the second cohort with respect to men; however, there was some evidence of an association in women after accounting for age and stroke risk factors [13]. Brown et al. [14] conducted a population-based casecontrol study of several measures of neighborhood disadvantage and stroke in New Zealand. The authors found an association between area-level income and the odds of stroke. After adjustment for individual-level income, ethnicity, and stroke risk factors there was some attenuation in the association but it remained significant $(\mathrm{OR}=0.77$ per USD 10,000 increase; $p<0.01$ ) [14]. In a recent analysis of data from the Health and Retirement Study, a population-based study of US elderly, Freedman et al. [15] considered the association between several neighborhood features and the odds of stroke (based on self-report) in a 2-year time period. In this analysis, there was an association between the neighborhood variable representing high crime, high racial segregation and odds of stroke among women $(\mathrm{OR}=1.16 ; 95 \% \mathrm{CI}: 1.00-1.35)$. This association remained but was no longer significant after accounting for sociodemographics including individuallevel SES, childhood health, smoking and region. Associations between other neighborhood features and stroke were not noted. Finally, in a recently published study by Clark et al. [16], investigators considered the association between perceived neighborhood cohesion and stroke incidence and mortality. They found that each 1-point increase in cohesion was associated with a $53 \%$ reduced risk of stroke mortality ( $\mathrm{HR}=0.47$; 95\% CI: $0.24-0.90)$ after adjusting for demographics, stroke risk factors, and arealevel SES. This association was modified by race such that cohesion was protective in whites but not African Americans. An association between cohesion and stroke incidence was not found.

\section{References}

1 Diez Roux AV, Mair C: Neighborhoods and health. Ann NY Acad Sci 2010;1186:125-145.

-2 Diez Roux AV: Residential environments and cardiovascular risk. J Urban Health 2003;80:569-589.

- 3 Engstrom G, Jerntorp I, Pessah-Rasmussen H, Hedblad B, Berglund G, Janzon L: Geographic distribution of stroke incidence within an urban population: relations to socioeconomic circumstances and prevalence of cardiovascular risk factors. Stroke 2001;32:1098-1103.

-4 Grimaud O, Bejot Y, Heritage Z, Vallee J, Durier J, Cadot E, Giroud M, Chauvin P: Incidence of stroke and socioeconomic neighborhood characteristics: an ecological analysis of Dijon stroke registry. Stroke 2011; 42:1201-1206.

5 Kleindorfer DO, Lindsell C, Broderick J, Flaherty ML, Woo D, Alwell K, Moomaw CJ, Ewing I, Schneider A, Kissela BM: Impact of socioeconomic status on stroke incidence: a population-based study. Ann Neurol 2006;60:480-484.

6 Lisabeth LD, Diez Roux AV, Escobar JD, Smith MA, Morgenstern LB: Neighborhood environment and risk of ischemic stroke: the Brain Attack Surveillance in Corpus Christi (BASIC) Project. Am J Epidemiol 2007;165:279-287.

-7 Smits J, Westert GP, van den Bos GA: Socioeconomic status of very small areas and stroke incidence in the Netherlands. J Epidemiol Community Health 2002;56:637-640.

8 Starr JM, Thomas B, Whalley LJ: Population risk factors for hospitalization for stroke in Scotland. Int J Epidemiol 1996;25:276-281.

-9 Thrift AG, Dewey HM, Sturm JW, Paul SL, Gilligan AK, Srikanth VK, Macdonell RA, McNeil JJ, Macleod MR, Donnan GA: Greater incidence of both fatal and nonfatal strokes in disadvantaged areas: the Northeast Melbourne Stroke Incidence Study. Stroke 2006;37:877882 .

10 Macleod MR, Andrews PJ: Effect of deprivation and gender on the incidence and management of acute brain disorders. Intensive Care Med 2002;28:1729-1734.

11 Morgenstern LB, Escobar JD, Sanchez BN, Hughes R, Zuniga BG, Garcia N, Lisabeth LD: Fast food and neighborhood stroke risk. Ann Neurol 2009;66:165-170.

12 Hart CL, Hole DJ, Smith GD: Influence of socioeconomic circumstances in early and later life on stroke risk among men in a Scottish cohort study. Stroke 2000;31:2093-2097.

13 Hart CL, Hole DJ, Smith GD: The contribution of risk factors to stroke differentials, by socioeconomic position in adulthood: the Renfrew/ Paisley Study. Am J Public Health 2000;90:1788-1791. 
14 Brown P, Guy M, Broad J: Individual socio-economic status, community socio-economic status and stroke in New Zealand: a case control study. Soc Sci Med 2005;61:1174-1188.

- 15 Freedman VA, Grafova IB, Rogowski J: Neighborhoods and chronic disease onset in later life. Am J Public Health 2011;101:79-86.

- 16 Clark CJ, Guo H, Lunos S, Aggarwal NT, Beck T, Evans DA, Mendes de Leon C, Everson-Rose SA: Neighborhood cohesion is associated with reduced risk of stroke mortality. Stroke 2011;42:1212-1217.

Lynda D. Lisabeth, PhD

Department of Epidemiology, University of Michigan 1415 Washington Heights, Ann Arbor, MI 48109 (USA)

Tel. +1 734936 9649, E-Mail llisabet@umich.edu

\section{Update on Stroke Risk Factor Management 20th European Stroke Conference, Hamburg, Germany, May 2011 Mini Symposium 5}

\section{1 \\ Update on Stroke Risk Factor Management: Hyperlipidemia}

\section{L.B. Goldstein}

Duke Stroke Center, Duke University and Durham VA

Medical Center, Durham, N.C., USA

The relationship between lipids and stroke is complex. There are several apparent and real paradoxes related to the association between cholesterol levels and stroke risk, as well as differing effects of lipid-lowering therapies on incident and recurrent stroke. Understanding these varying relationships is important as they have direct implications for stroke preventive care.

Epidemiological studies highlight the first apparent paradox - the association between lipid levels and the risk of stroke as compared to coronary heart disease. The Prospective Studies Collaboration investigated the relationship between cholesterol levels and cause-specific mortality based on individual data on 900,000 adults without any previous vascular disease from 61 prospective cohort studies [1]. The risks of death from ischemic heart disease increased with increasing levels of usual cholesterol from 155 to $309 \mathrm{mg} / \mathrm{dl}$ across all age groups (10-year increments between ages 40 and 89 years). In contrast, there was no overall relationship between increasing usual cho- lesterol levels over this same range and the risk of fatal stroke, with the possible exception of levels above about $270 \mathrm{mg} / \mathrm{dl}$ in those age $40-59$ years. This paradox may be explained by the lack of consideration of stroke subtypes in many epidemiological studies. The distinction can be important as the Prospective Studies Collaboration notes a possible inverse relationship between cholesterol levels and hemorrhagic stroke. Other epidemiological studies have found a similar association. For example, the Asian Pacific Cohort study reported a 25\% (95\% CI 13-40) increased risk of ischemic stroke per $4.5-\mathrm{mg} / \mathrm{dl}$ increase in total cholesterol, but a $20 \%(95 \%$ CI 8-30) decreased risk of hemorrhagic stroke for the same increase in cholesterol concentration [2]. The overall lack of relationship between cholesterol levels and stroke found by the Prospective Studies Collaboration may, in part, be due to these competing risks; lower levels of usual cholesterol can be associated with a higher risk of brain hemorrhage whereas higher levels can be associated with a higher risk of ischemic stroke.

These data have important implications for primary stroke prevention as most studies in Western populations indicate that about $80 \%$ of strokes are ischemic, but lead to a second apparent paradox. It would reasonably be anticipated that measures to lower cholesterol levels would generally translate into lower stroke risk. Meta-analysis, however, finds no reduction in stroke risk with dietary intervention to lower cholesterol (10 trials; risk ratio, $\mathrm{rr}=$ $0.99,95 \%$ CI $0.85-1.15$ ), fibrates (11 trials, $r r=1.05,95 \%$ CI 0.92-1.19), resins (4 trials, $\mathrm{rr}=1.03,95 \%$ CI $0.54-2.00$ ) or omega-3 fatty acids ( 8 trials, $\mathrm{rr}=0.91,95 \%$ CI $0.56-$ 1.48) [3]. In contrast, treatment of patients with coronary heart disease or specific vascular risk factors such as diabetes, hypertension, or elevated high-sensitivity C-reactive protein with an HMG-CoA reductase inhibitor (statins) is associated with a $19 \%$ lower risk of a first stroke (relative risk 0.81, 95\% CI 0.75-0.87) [4]. Every 10\% decrease in LDL cholesterol was associated with a $13.5 \%$ (95\% CI 7.7-18.8\%) reduction in the risk of a first stroke. It cannot be determined from clinical trials whether the difference in efficacy between statins and non-statin therapy is due to statin's more potent lipid-lowering effects or to one or a combination of statin's non-lipid lowering (i.e. 'pleiotropic') properties [5].

Although ample evidence is available supporting the efficacy of statins for primary stroke prevention in patients with coronary heart disease or other high-risk conditions, there are only a few studies with data evaluating their effects in patients with established cerebrovascular disease. One is the Heart Protection Study, which ran- 


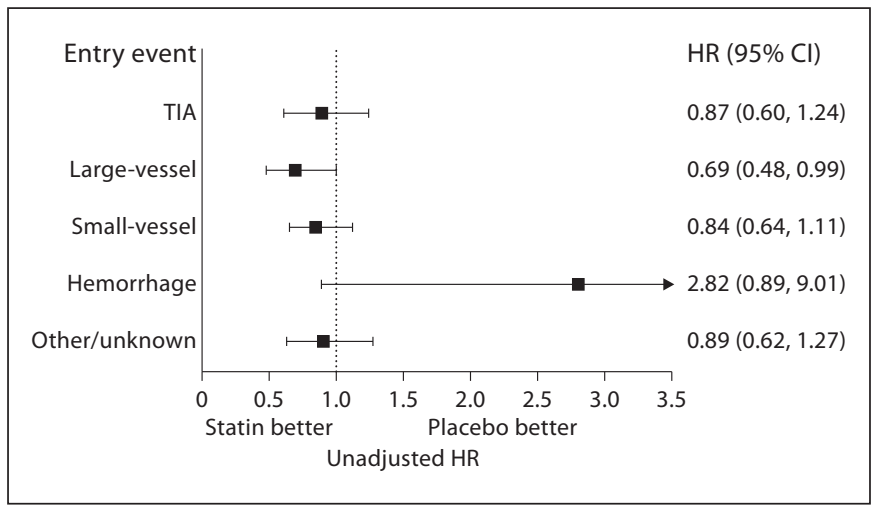

Fig. 1. SPARCL trial: effect of statin treatment on the risk of recurrent stroke based on index stroke subtype. Data from Goldstein et al. [14].

domized 20,536 high-risk patients (including 3,280 with prior stroke) to treatment with simvastatin ( $40 \mathrm{mg} /$ day) or placebo [6]. Randomization to the statin led to a $24 \%$ reduction (rate ratio $0.76,95 \%$ CI $0.72-0.81$ ) in major vascular events that was similar in those with and without prior stroke. There was also an overall $25 \%$ reduction in stroke with statin treatment (rate ratio $0.75,95 \%$ CI 0.66 0.85 ), but the effect varied based on stroke history; there was no stroke reduction in those with prior stroke $(10.3 \%$ of those with prior stroke who were treated with the statin had a second stroke vs. $10.4 \%$ of those treated with placebo). Thus, unlike primary prevention, the Heart Protection Study provides no evidence that statins are helpful for secondary stroke prevention - another apparent paradox. Possible explanations for the lack of effect include that the stroke subgroup analysis was unplanned, lacked sufficient statistical power, that the particular statin or dose was inadequate, and that the study likely included many patients at relatively low risk of recurrent stroke (patients were randomized an average of 4.3 years after the index event; the highest risk of recurrent stroke is over the first months or years) [7]. Alternatively, statins might not be helpful for secondary stroke prevention.

The Stroke Prevention with Aggressive Reduction in Cholesterol Levels (SPARCL) trial was specifically designed and powered to test the effects of a statin (atorvastatin $80 \mathrm{mg} /$ day) in patients with recent (within 6 months) noncardioembolic stroke or transient ischemic attack and no known coronary heart disease (these patients had an established indication for statin treatment), who had a baseline LDL cholesterol between 100 and 190 $\mathrm{mg} / \mathrm{dl}$ [8]. LDL cholesterol decreased from $133 \mathrm{mg} / \mathrm{dl}$ at baseline to $73 \mathrm{mg} / \mathrm{dl}$ in those randomized to the statin versus $129 \mathrm{mg} / \mathrm{dl}$ in those randomized to placebo. Added to otherwise best medical therapy, statin treatment led to a $16 \%$ (adjusted hazard ratio, HR $=0.84,95 \%$ CI $0.71-$ $0.99)$ reduction in the risk of fatal or nonfatal stroke, providing clear evidence of benefit for secondary stroke prevention. Although subjects who had known coronary heart disease were excluded, those in the statin group also had lower rates of major coronary events $(\mathrm{HR}=0.65,95 \%$ CI 0.49-0.87), major cardiovascular events ( $\mathrm{HR}=0.80$, 95\% CI 0.69-0.92), any coronary heart event $(\mathrm{HR}=0.58$, $95 \%$ CI $0.46-0.73$ ), and any revascularization procedure (HR $=0.55,95 \%$ CI 0.43-0.72) [8]. Subsequent secondary analyses found the benefit was similar in men and women [9], in those younger and older than age 65 years [10], in those with or without carotid stenosis [11], and regardless of the presence or absence of diabetes or the metabolic syndrome [12].

Exploratory analysis of SPARCL data also found that the benefit of statin treatment was similar regardless of ischemic stroke subtype [13]. About 2\% of SPARCL subjects had an index hemorrhagic stroke with inclusion in the trial based on the investigator's view that the patient was also at risk for ischemic events [8]. In contrast to those with ischemic stroke, there was no evidence that those with hemorrhagic stroke at baseline had treatmentrelated reductions in either recurrent stroke or major vascular events $[13,14]$. Stroke risk actually tended to be higher in this subgroup (fig. 1), and the overall benefit of statin treatment in reducing fatal and nonfatal stroke was partially attenuated by a significantly increased risk of brain hemorrhage $[8,14]$. This finding presents yet another apparent paradox. As noted, epidemiological studies generally find that low levels of usual cholesterol are associated with an increased risk of brain hemorrhage. Yet, primary prevention studies find no statin-associated increased risk of hemorrhagic stroke [4], even if lipids are lowered to levels similar to those achieved in SPARCL (i.e. mean $77 \mathrm{mg} / \mathrm{dl}$ ) [15]. Exploratory analyses found that the risk of an outcome brain hemorrhage in SPARCL was independently associated with statin treatment, male sex, increasing age, uncontrolled hypertension at the visit prior to the hemorrhage, and having a hemorrhage at baseline [14]. There was no statistical interaction between any of these factors (i.e. the risk of brain hemorrhage was not disproportionately higher in statin-treated subjects with a hemorrhage at baseline or in those with uncontrolled hypertension). There were no independent relationships between absolute LDL cholesterol levels or the relative degree of cholesterol-lowering and hemorrhagic stroke risk $[14,16]$. This suggests that the statin-associated increased 
risk of hemorrhagic stroke in patients with recent stroke may be due to one or a combination of the drug's nonlipid lowering effects. Although based on secondary, exploratory analyses, in addition to careful control of blood pressure, it seems prudent to avoid statin treatment soon after a brain hemorrhage.

Data from both the laboratory and clinical trials are necessary to help explain seemingly paradoxical associations between lipid levels and stroke risk in general populations, as well as the differing impact of statin therapy on the risk of ischemic and hemorrhagic stroke in primary and secondary prevention settings. Used judiciously, statins can be an important component of an overall stroke preventive regimen.

\section{Disclosure Statement}

Dr. Goldstein is a member of the Steering Committee for the SPARCL trial and has served as a consultant for Pfizer.

\section{References}

1 Prospective Studies Collaboration: Blood cholesterol and vascular mortality by age, sex, and blood pressure: a meta-analysis of individual data from 61 prospective studies with 55,000 vascular deaths. Lancet 2007;370:1829-1839.

-2 Zhang X, Patel A, Horibe H, Wu Z, Barzi F, Rodgers A, MacMahon S, Woodward M: Cholesterol, coronary heart disease, and stroke in the Asia Pacific region. Int J Epidemiol 2003;32:563-572.

- 3 Briel M, Studer M, Glass TR, Bucher HC: Effects of statins on stroke prevention in patients with and without coronary heart disease: a metaanalysis of randomized controlled trials. Am J Med 2004;117:596-606.

-4 Amarenco P, Labreuche J: Lipid management in the prevention of stroke: review and updated meta-analysis of statins for stroke prevention. Lancet Neurol 2009;8:453-463.

5 Goldstein LB: Statins and ischemic stroke severity: cytoprotection. Curr Atheroscler Rep 2009;11:296-300.

-6 Heart Protection Study Collaborative Group: Effects of cholesterollowering with simvastatin on stroke and other major vascular events in 20,536 people with cerebrovascular disease or other high-risk conditions. Lancet 2004;363:757-767.

7 Goldstein LB, Amarenco P, Bogousslavsky J, Callahan AS, Hennerici MG, Welch KMA, Zivin J, Sillesen H: Statins for secondary stroke prevention in patients without known coronary heart disease: the jury is still out. Cerebrovasc Dis 2004;18:1-2.

8 The Stroke Prevention by Aggressive Reduction in Cholesterol Levels (SPARCL) Investigators: High-dose atorvastatin after stroke or transient ischemic attack. N Engl J Med 2006;355:549-559.

$\checkmark 9$ Goldstein LB, Amarenco P, LaMonte M, Gilbert S, Messig M, Callahan A, Hennerici M, Sillesen H, Welch KMA: Relative effects of statin therapy on stroke and cardiovascular events in men and women. Secondary analysis of the Stroke Prevention by Aggressive Reduction in Cholesterol Levels (SPARCL) study. Stroke 2008;39:2444-2448.

10 Chaturvedi S, Zivin J, Breazna A, Amarenco P, Callahan A, Goldstein LB, Hennerici M, Sillesen H, Rudolph A, Welch KMA: Effect of atorvastatin in patients age 65 and over with a recent stroke or transient ischemic attack. Neurology 2009;72:688-694.
11 Sillesen H, Amarenco P, Hennerici M, Callahan A, Goldstein LB, Zivin J, Messig M, Welch KM: Atorvastatin reduces the risk of cardiovascular events in patients with carotid atherosclerosis. A Secondary Analysis of the Stroke Prevention by Aggressive Reduction in Cholesterol Levels (SPARCL) trial. Stroke 2008;39:3297-3302.

- 12 Callahan A, Amarenco P, Goldstein LB, Sillesen H, Messig M, Samsa GP, Altafullah IM, Ledbetter LY, MacLeod MJ, Scott R, Hennerici M, Zivin J, Welch KMA; for the SPARCL Investigators: Risk of stroke and cardiovascular events after ischemic stroke or transient ischemic attack in patients with type 2 diabetes or metabolic syndrome. Arch Neurol 2011;68:1245-1251.

13 Amarenco P, Benavente O, Goldstein LB, Callahan A, Sillesen H, Hennerici M, Gilbert S, Rudolph A, Simunovic L, Zivin J, Welch KMA: Results of the Stroke Prevention by Aggressive Reduction in Cholesterol Levels (SPARCL) Trial by stroke subtypes. Stroke 2009;40:1405-1409.

14 Goldstein LB, Amarenco P, Szarek M, Callahan A, Hennerici M, Sillesen H, Zivin J, Welch KMA: Secondary analysis of hemorrhagic stroke in the Stroke Prevention by Aggressive Reduction in Cholesterol Levels (SPARCL) Study. Neurology 2008;70:2364-2370.

- 15 Waters DD, LaRosa JC, Barter P, Fruchart JC, Gotto AM Jr, Carter R, Breazna A, Kastelein JJ, Grundy SM: Effects of high-dose atorvastatin on cerebrovascular events in patients with stable coronary disease in the TNT (Treating to New Targets) study. J Am Coll Cardiol 2006;48: 1793-1799.

16 Amarenco P, Goldstein LB, Szarek M, Sillesen H, Rudolph AE, Callahan A, Hennerici M, Simunovic L, Zivin JA, Welch KMA: Effects of intense low-density lipoprotein cholesterol reduction in patients with stroke or transient ischemic attack: the Stroke Prevention by Aggressive Reduction in Cholesterol Levels (SPARCL) trial. Stroke 2007;38:3198-3204.

Larry B. Goldstein, MD

Duke University Medical Center

Box 3651

Durham, NC 27710 (USA)

Tel. +1 919684 3801, E-Mail golds004@mc.duke.edu

\section{2}

\section{Hyperhomocystinaemia}

\author{
G.J. Hankey \\ Stroke Unit, Department of Neurology, Royal Perth \\ Hospital, and School of Medicine and Pharmacology, \\ University of Western Australia, Perth, W.A., Australia
}

\section{What Is Homocysteine?}

Homocysteine is an amino acid derived from methionine, which is abundant in animal sources of protein. The pathway that converts methionine to homocysteine is essential for proper functioning of many molecules including DNA, proteins and phospholipids [1]. Homocysteine then acquires a methyl group from 5-methyltetrahydrofolate (a reaction that is vitamin $\mathrm{B}_{12}$-dependent) or from betaine to re-form methionine, or is metabolized to cystathionine in a reaction catalyzed by cystathionine-synthase and requiring vitamin $\mathrm{B}_{6}[1]$. The combined pool of 
free, bound, reduced and oxidized forms of homocysteine in the blood is the total plasma (or total serum) homocysteine (tHcy).

\section{What Is Hyperhomocysteinaemia?}

Hyperhomocysteinaemia is a fasting plasma tHcy concentration that is elevated. The cut-off level is most commonly defined arbitrarily as above the 95th percentile of values obtained from the so-called normal population. Each laboratory establishes reference limits for its own region, with separate reference limits for children (usually $<8 \mu \mathrm{mol} / \mathrm{l})$, adults $(<12 \mu \mathrm{mol} / \mathrm{l})$, the elderly $(<16 \mu \mathrm{mol} / \mathrm{l})$, and pregnant women $(<8 \mu \mathrm{mol} / \mathrm{l})$ [1]. For populations taking folic acid supplements or eating a folic-acid fortified diet, the upper reference limit is generally $20-25 \%$ lower than for populations not receiving extra folic acid [1].

\section{Why May Hyperhomocysteinaemia Be Important?}

Systematic reviews of observational studies have consistently shown a strong, positive, and dose-related association between increasing serum concentrations of tHcy and the risk of stroke, which is independent of other vascular risk factors [2-4]. The association is biologically plausible [5] and homocysteine can be lowered by about 25\% (95\% CI: 23-28\%) with folic acid supplementation and by about $7 \%$ (95\% CI: 3-10\%) with vitamin $\mathrm{B}_{12}$ supplementation [6]. If the association between hyperhomocysteinaemia and stroke is causal, lowering tHcy by means of folic acid supplementation (a widely available, safe and affordable B vitamin) could substantially reduce the global burden of stroke.

\section{Is Hyperhomocysteinaemia a Causal and Treatable Risk Factor for Stroke?}

Observational studies reporting an independent, significant association between hyperhomocysteinaemia and stroke cannot eliminate bias and confounding [7]. The stronger association between tHcy and stroke reported in retrospective studies (in which researchers collected blood after stroke) than prospective studies may reflect reverse causality bias (i.e. acute stroke may increase tHcy). Moreover, the association between tHcy and stroke could be confounded by failure to record or adjust for known and unknown factors that increase both tHcy and stroke risk (e.g. smoking, lower socioeconomic class, existing atherosclerosis, and renal impairment) [1]. The best method to minimize bias and confounding, and establish causality, is by randomization, and the best method of minimizing random error (chance) is by a systematic review and meta-analysis of randomized controlled trials (RCTs).

A meta-analysis of eight large randomized placebocontrolled trials of folic acid supplementation in 37,485 patients showed that, despite yielding an average $25 \%$ reduction in homocysteine concentration, allocation to folic acid had no effect on the rate of occurrence of 1,528 first strokes (RR 0.96, 95\% CI: 0.87-1.06) and 9,326 first major vascular events (RR 1.01, 95\% CI: 0.97-1.05) over a median follow-up of 5 years [8]. These findings were consistent among the prespecified subgroups including patient age, sex, folate level, and homocysteine level; folate fortification; year of follow-up, and clinical trial. There was also no evidence of a dose-response relationship; trials with greater reductions in tHcy among patients assigned folic acid did not report concurrent greater reductions in stroke or major vascular events - the absence of effect of folic acid on stroke and major vascular events was consistent, irrespective of the percentage reduction in tHcy [8].

Subsequent to this meta-analysis, two additional placebo-controlled trials of folic acid supplementation in another 10,665 patients $(8,654$ with prior stroke or transient ischaemic attack) also reported no statistically significant benefit of folic acid supplementation in preventing stroke or major vascular events $[9,10]$. However, when these trial data are added to an updated meta-analysis, random allocation to $\mathrm{B}$ vitamins was associated with a reduction in stroke compared with placebo $[1,041 / 25,261 \mathrm{~B}$ vitamins vs. 1,060/21,879 placebo, risk ratio (RR) $0.91,95 \%$ CI: $0.83-$ $0.99]$ and a trend toward a reduction in stroke compared with any control $(1,213 / 27,570$ vs. $1,216 / 24,043$; RR 0.93 , 95\% CI: 0.86-1.00) (fig. 1) [9]. There was no significant effect on the composite of stroke, myocardial infarction or vascular death $(3,832 / 21,632 \mathrm{~B}$ vitamins vs. $3,539 / 19,805$ control; RR 0.98, 95\% CI: 0.94-1.03) (fig. 2) [9]. These analyses raise the hypothesis that the current meta-analyses of randomized controlled trials of folic acid supplementation (i.e. the current evidence base) may still be underpowered statistically to reliably exclude a modest but clinically important treatment effect of folic acid on the risk of stroke [11].

The findings of the RCTs are consistent with those of a recent meta-analysis of 237 genetic epidemiological studies, in which dietary folate status, tHcy and the presence of the methylene tetrahydrofolate reductase (MTHFR) C677T polymorphism in 60,000 individuals 


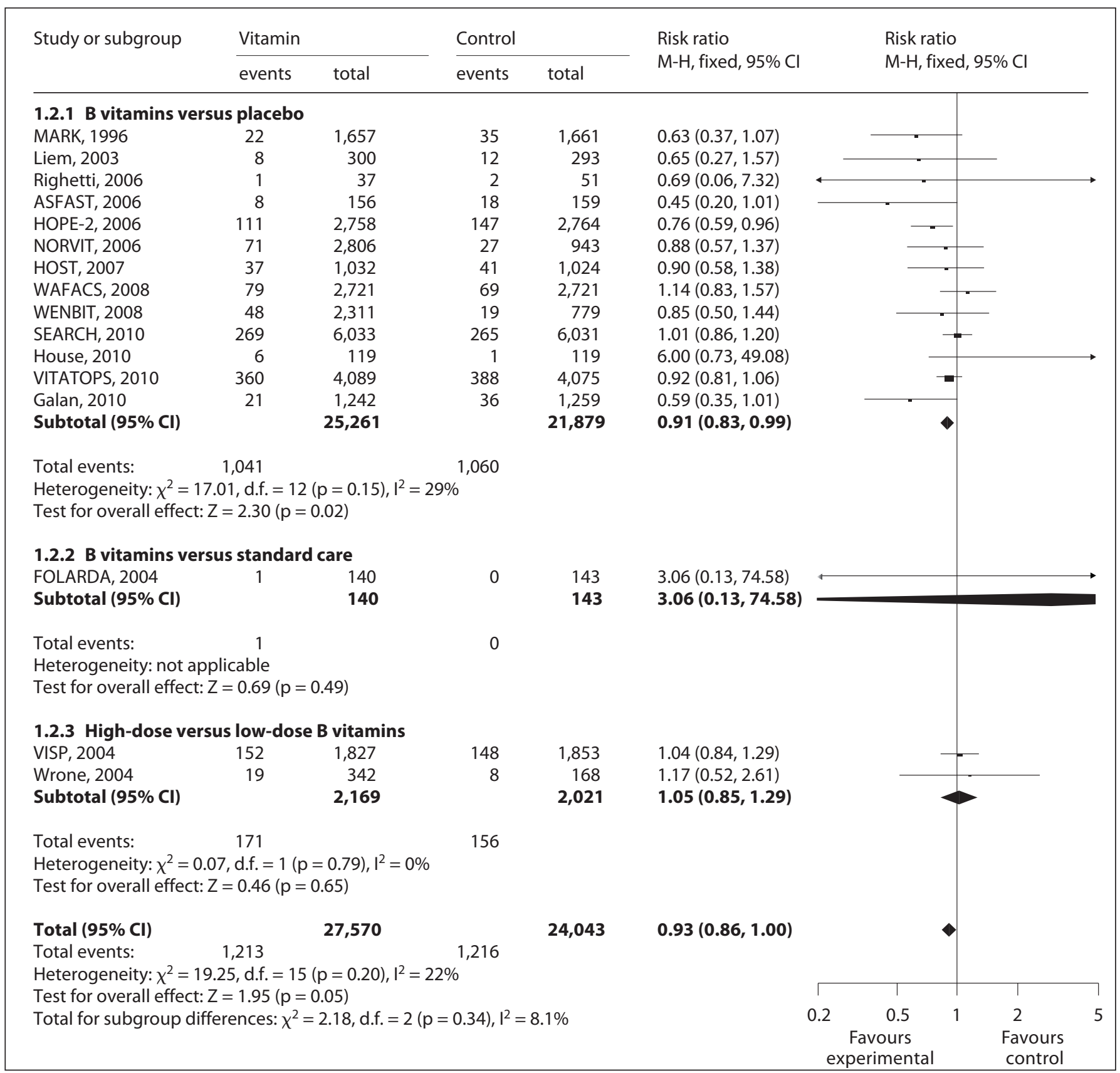

Fig. 1. Meta-analysis of RCTs evaluating the effects of treatment with B vitamins compared with control on the occurrence of stroke. M-H = Mantel-Haenszel.

were correlated with the occurrence of 20,885 subsequent stroke events [12]. Dietary folate status was categorized from the lowest to the highest: (1) no fortification (Asia, north and sub-Saharan Africa); (2) low (prefortification in 1996: Europe); (3) mid (postfortification in 1996: Europe); (4) mid (prefortification: America, Australia, and New Zealand before 1996; Central and South America);
(5) high postfortification (America, Australia, and New Zealand after 1996, Chile after 2000) [12]. The study reported three major results [12].

First, compared with the CC genotype of the gene that encodes the MTHFR enzyme, the $10 \%$ of the general population who undergo natural (Mendelian) randomization at conception to the TT genotype (i.e. MTHFR $677 \mathrm{C} \rightarrow$ 


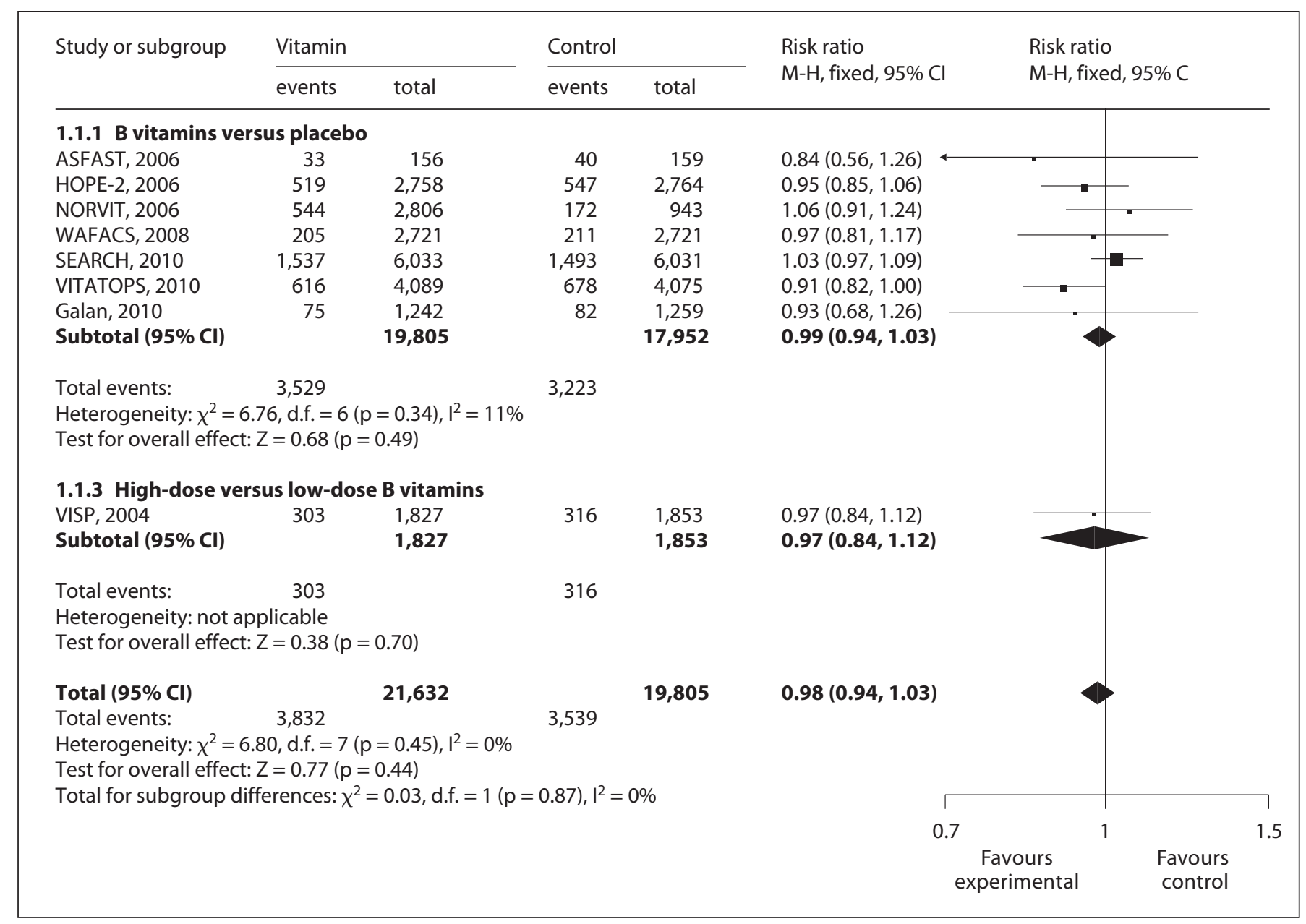

Fig. 2. Meta-analysis of RCTs evaluating the effects of treatment with B vitamins compared with control on the occurrence of the composite of non-fatal stroke, non-fatal myocardial infarction, or death due to vascular causes. $\mathrm{M}-\mathrm{H}=$ Mantel-Haenszel.

T polymorphism) had higher plasma concentrations of tHcy in low folate regions $(3.12 \mu \mathrm{mol} / \mathrm{l}, 95 \% \mathrm{CI}: 2.23-$ 4.01) than in high folate regions $(0.13 \mu \mathrm{mol} / \mathrm{l}, 95 \% \mathrm{CI}$ : -0.85 to 1.11 ) [12].

Second, the effect of the MTHFR/C677T variant (TT vs. CC genotype) on the risk of stroke was higher in low folate regions (odds ratio 1.68, 95\% CI: 1.44-1.97) than in high folate regions (1.03, 95\% CI: 0.84-1.25).

Third, the genetic epidemiological studies predicted a lack of effect on stroke risk of lowering tHcy to the same degree that was observed in the RCTs of tHcy-lowering interventions in the folate-fortified non-Asian regions (where most of the RCTs took place) which was similar (relative risk 1.00, 95\% CI: $0.90-1.11$ ) to that which was observed in the RCTs (RR 0.94, 95\% CI: 0.85-1.04) [12].
In contrast, for low folate regions, such as Asia, the large genetic studies predicted that lowering homocysteine by $3.8 \mu \mathrm{mol} / \mathrm{l}$ would significantly reduce the rate of stroke by about $22 \%$ (RR $0.78,95 \%$ CI: $0.68-0.90$ ) but there have been no large, reliable RCTs to explore this hypothesis in exclusively low folate regions such as Asia.

The concordant results from the meta-analyses of RCTs and genetic epidemiological studies suggest that in regions with established or increasing folate intake there is likely to be no benefit from lowering tHcy in preventing stroke. However, in regions of low folate intake (e.g. Asia), it is possible that supplementation of the diet, or fortification of food, with folic acid and vitamin $\mathrm{B}_{12}$ may reduce the incidence of stroke. 
The current evidence is not sufficiently robust to support a policy of giving B vitamin supplements for secondary prevention after transient ischaemic attack or minor stroke. However, there is still a place for further trials of homocysteine-lowering treatment, particularly in low folate regions, and especially if the intervention can achieve and sustain large reductions in homocysteine over prolonged periods. Alternatively, it may be more pragmatic and cost-effective to immediately fortify food in low folate regions, such a Asia, with folic acid.

\section{Disclosure Statement} [9].

G.J.H. was the principal investigator of the VITATOPS trial

\section{References}

1 Hankey GJ, Eikelboom JW, Ho WK, van Bockxmeer FM: Clinical usefulness of plasma homocysteine in vascular disease. Med J Aust 2004 181:314-318.

2 Homocysteine Studies Collaboration: Homocysteine and risk of ischemic heart disease and stroke: a meta-analysis. JAMA 2002;288:20152022.

3 Wald DS, Wald NJ, Morris JK, Law M: Folic acid, homocysteine and cardiovascular disease: judging causality in the face of inconclusive trial evidence. BMJ 2006;333:114-117.

4 Hankey GJ, Eikelboom JW: Homocysteine and stroke. Lancet 2005; 365:194-196.

5 Faraci FM, Lentz SR: Hyperhomocysteinemia, oxidative stress, and cerebral vascular dysfunction. Stroke 2004;35:345-347.

-6 Homocysteine Lowering Trialists' Collaboration: Dose-dependent effects of folic acid on blood concentrations of homocysteine: a metaanalysis of the randomized trials. Am J Clin Nutr 2005;82:806-812.

7 Lawlor DA, Davey Smith G, Kundu D, Bruckdorfer KR, Ebrahim S: Those confounded vitamins: what can we learn from the differences between observational versus randomised trial evidence? Lancet 2004; 363:1724-1727.

8 Clarke R, Halsey J, Lewington S, Lonn E, Armitage J, Manson JE, Boxnaa KH, Spence JD, Nygård O, Jamison R, Gaziano JM, Guarino P, Bennett D, Mir F, Peto R, Collins R; for the B-Vitamin Treatment Trialists Collaboration: Effects of lowering homocysteine levels with B vitamins on cardiovascular disease, cancer, and cause-specific mortality: metaanalysis of 8 randomized trials involving 37,485 individuals. Arch Intern Med 2010;170:1622-1631.

-9 VITATOPS Trial Study Group: B vitamins in patients with recent transient ischaemic attack or stroke in the VITAmins TO Prevent Stroke (VITATOPS) trial: a randomised, double-blind, parallel, placebo-controlled trial. Lancet Neurol 2010;9:855-865.

10 Galan P, Kesse-Guyot E, Czernichow S, Briancon S, Blacher J, Hercberg S, for the SU.FOL.OM3 Collaborative Group: Effects of B vitamins and omega 3 fatty acids on cardiovascular diseases: a randomised placebo controlled trial. BMJ 2010;341:c6273.

11 Sandercock P: Vitamin B supplements for prevention of stroke. Lancet Neurol 2010;9:842-843.

12 Holmes MV, Newcombe P, Hubacek JA, Sofat R, Ricketts SL, Cooper J, Breteler M, Bautista LE, Sharma P, Whittaker J, Smeeth L, Fowkes GR, Algra A, Shmeleva V, Szolnoki Z, Roest M, Linnebank M, Zacho J, Nalls MA, Singleton AB, Ferrucci L, Hardy J, Worrall BB, Rich S, Matarin M,
Norman PE, Flicker L, Almeida OP, van Bockxmeer F, Shimokata H, Khaw K-T, Wareham N, Bobak M, Sterne JAC, Davey Smith G, Talmud PJ, van Duijn C, Humphries SE, Price J, Ebrahim S, Lawlor DA, Hankey GJ, Meschia JF, Sandhu MS, Hingorani AD, Casas JP: Effect modification by population dietary folate on the association between MTHFR genotype, homocysteine, and stroke risk: a meta-analysis of genetic studies and randomised trials. Lancet 2011;378:584-594.

Prof. Graeme J. Hankey

Stroke Unit, Department of Neurology

Royal Perth Hospital, 197 Wellington Street

Perth, WA 6001 (Australia)

Tel. +61 89224 2598, E-Mail gjhankey@cyllene.uwa.edu.au

\section{3 \\ Diabetes Mellitus and Stroke}

M.G. Hennerici

Department of Neurology, UMM, University of

Heidelberg, Mannheim, Germany

\section{Epidemiology}

The number of people suffering from diabetes mellitus is continuously increasing and 'has soared to $366 \mathrm{mil}-$ lion - the disease kills one person every seven seconds, posing a massive challenge to health care systems worldwide' (www.reutersreprints.com, Sept. 13, 2011). Type 2 diabetes accounts for $90 \%$ of those with the disease, largely routed in reversible social and lifestyle factors, such as poor diet, obesity and lack of exercise spreading from Western lifestyles in the developing world.

Data from 698,782 people from 102 prospective studies recently published by the Emerging Risk Factors Collaboration [1] showed that diabetes mellitus can lead to serious complications such as coronary heart disease, including coronary death and non-fatal myocardial infarction, as well as ischaemic and haemorrhagic strokes. If associated with increasing age and risk factors of atherosclerosis (e.g. smoking, hypercholesterolaemia and hypertension), type 2 diabetes mellitus is often diagnosed on the basis of sustained hyperglycaemia. Inadequate blood sugar control is best monitored by glycated haemoglobin (HbAlc) values: the higher the percentage of $\mathrm{HbAlc}$, the bigger the risk of cardiovascular disease, stroke and death [2]. Adjusted hazard ratios (HR, 95\% CI) for clinical outcome during a 15 -year study period demonstrated a significant increase for poor outcome for HbAlc 5.5 to $<6.0,6.0$ to $<6.5$ and $>6.5$ of $1.27(0.97-1.67), 2.63(1.92-3.61)$ and 3.68 (2.565.30; $\mathrm{p}<0.001)$, respectively [2]. 


\section{Failure to Demonstrate Benefit from Intensive HbA1c Control on Clinical Outcome}

The Action to Control Cardiovascular Risk in Diabetes (ACCORD) study group investigated 10,251 patients (mean age 62.2 years) with a mean glycated haemoglobin level of $8.1 \%$ assigned to receive either intensive therapy targeting the HbAlc level below $6.0 \%$ or standard therapy targeting a level from 7 to $7.9 \%[3,4]$. The aim of the study was to test whether intensive therapy would reduce cardiovascular events in patients with type 2 diabetes, who had either established cardiovascular disease or additional cardiovascular risk factors at entry. After 1-year followup, the primary outcome (a composite of nonfatal myocardial infarction, nonfatal stroke, or death from cardiovascular causes) occurred in 352 patients in the intensive therapy group as compared with 371 in the standard therapy group (HR 0.90; 95\% CI 0.78-1.04; $\mathrm{p}=0.16$ ). At the same time 257 patients in the intensive therapy group died as compared with 203 patients in the standard therapy group (HR 1.22; 95\% CI 1.01-1.46; $\mathrm{p}=0.04$ ). HbAlc levels achieved were 6.4 and $7.5 \%$, respectively. Thus in contrast to expectations these findings identified a previously unrecognized harm of intensive glucose lowering in high risk patients with type 2 diabetes mellitus (fig. 1).

Long-term effects from the same study were recently published (5-year outcomes of a mean of 3.7 years of intense glucose lowering on mortality and key vascular events) [4]. Again in agreement with the short-term findings the intensive therapy group did not differ significantly from the standard therapy group in the rate of primary outcomes $(\mathrm{p}=0.13)$ but had more deaths from any cause (primarily cardiovascular, HR 1.21; 95\% CI 1.011.44), although fewer non-fatal myocardial infarctions (HR 0.79; 95\% CI 0.66-0.95). In contrast, the incidence of non-fatal stroke did not differ between both therapy groups (fig. 2). Thus the strategy of intensive glucose lowering (counselling about lifestyle and education about the management of diabetes as well as glucose lowering drugs and regular control of HbAlc levels) could not be recommended.

Reasons for the higher mortality in the intensive therapy group remained unclear: neither severe hypoglycaemia nor the degree of reduced HbAlc levels, combinations of various drugs or drug interactions or the observed associations with other risk factors (e.g. hypertension and hyperglycaemia as well as their management) could be implicated. However, while all patients in ACCORD had had diabetes for a median of 10 years, the intervention period of 3.7 years was relatively short - hence, the design of the study might have been underpowered to introduce significant beneficial changes on late mortality in patients with already promoted atherosclerosis. One may assume, therefore, that people with newly diagnosed diabetes not included in the trial might have a different response to intensive glucose lowering therapy. This was shown in another large trial of 5,102 patients with differently targeted HbAlc levels (7\% as opposed to $7.9 \%$ in the ACCORD trial) demonstrating persisting relative risk reductions at 10 years: for any diabetes-related end-point ( $p=0.04)$, microvascular disease $(\mathrm{p}=0.001)$ and death from any cause $(\mathrm{p}=0.007)$, but no significant changes in stroke recurrences (HR 0.91; 95\% CI 0.73-1.13) [5].

\section{Failure to Demonstrate Benefit from Intensive HbA1c Control on Microvascular Outcome}

Diabetes mellitus is associated with hypoglycaemiaspecific microvascular complications in addition to a 2to 4-fold risk of large-vessel diseases causing cardiovascular disease including stroke. Several randomized clinical trials (RCTs) have demonstrated a significant reduction in the development of progressive diabetic retinopathy, nephropathy and neuropathy among patients treated intensively versus standard groups (DCCT and UKPDS) $[6,7]$. In contrast, in the ACCORD trial intensive treatment did not reduce the risk of advanced measures of microvascular outcomes but only delayed the onset of albuminuria and some measures of eye complications and neuropathy [8]. However, consistent with the ACCORD trial, both the DCCT and the UKPDS trials showed a trend towards lower risks of large-vessel associated cardiovascular events with intensive control. Because of permanent uncertainties regarding epidemiological studies and meta-analysis versus RCTs, the Action in Diabetes and Vascular Disease - Preterax and Diamicron Modified Release Controlled Evaluation (ADVANCE) and the Veterans Affairs Diabetes Trial (VADT) were completed in $2008[9,10]$. Both failed to show a significant reduction in cardiovascular outcome with intensive glycaemic control.

Again the discussion about these disappointing results concluded that beneficial effects from current strategies for treating hypoglycaemia in patients with advanced type 2 diabetes might have been counterbalanced by risks associated with intensive treatment, such as hypoglycaemia, weight gain or other metabolic changes. While these patients do not benefit from intensive management to control 


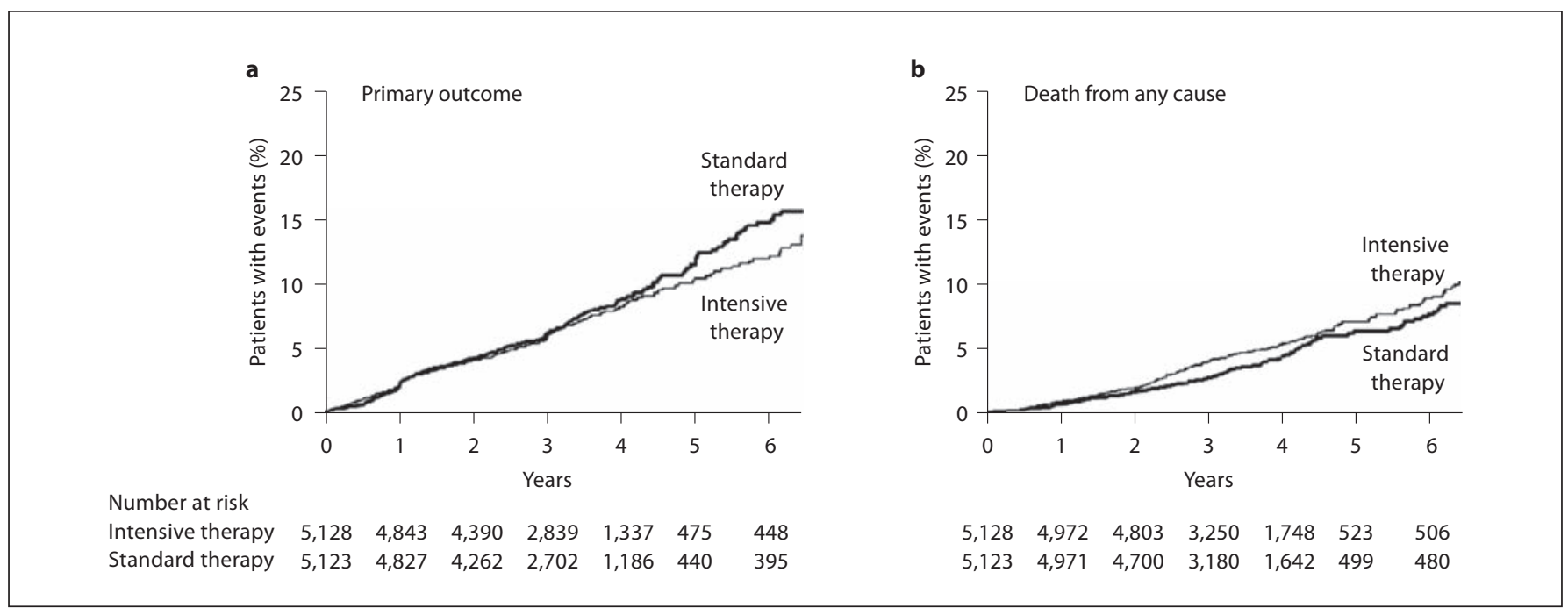

Fig. 1. Kaplan-Meier curves for the primary outcome and death from any cause [with permission from ref. 3].

\begin{tabular}{|c|c|c|c|c|c|}
\hline Outcome & $\begin{array}{l}\text { Intensive } \\
\text { No. of events (\%) }\end{array}$ & $\begin{array}{l}\text { Standard } \\
\text { No. of events (\%) }\end{array}$ & Hazard ratio $(95 \% \mathrm{Cl})$ & $\begin{array}{l}\text { Hazard ratio } \\
(95 \% \mathrm{Cl})\end{array}$ & $\begin{array}{l}p \text { value for } \\
\text { interaction }\end{array}$ \\
\hline \multicolumn{6}{|l|}{ Primary outcome } \\
\hline Before transition & $380(2.0)$ & $414(2.2)$ & & $0.90(0.78-1.03)$ & 0.13 \\
\hline Until end of study & $503(2.1)$ & $543(2.2)$ & & $0.91(0.81-1.03)$ & 0.12 \\
\hline \multicolumn{6}{|c|}{ Nonfatal myocardial infarction } \\
\hline Before transition & $207(1.1)$ & $257(1.4)$ & $\square$ & $0.79(0.66-0.95)$ & 0.01 \\
\hline Until end of study & $287(1.2)$ & $344(1.4)$ & & $0.82(0.70-0.96)$ & 0.01 \\
\hline \multicolumn{6}{|l|}{ Nonfatal stroke } \\
\hline Before transition & $72(0.4)$ & $72(0.4)$ & & $0.99(0.72-1.38)$ & 0.98 \\
\hline Until end of study & $82(0.3)$ & $94(0.4)$ & & $0.87(0.65-1.17)$ & 0.35 \\
\hline \multicolumn{6}{|c|}{ Death from cardiovascular causes } \\
\hline Before transition & $140(0.7)$ & $109(0.6)$ & & $1.27(0.99-1.63)$ & 0.07 \\
\hline Until end of study & $187(0.7)$ & $144(0.6)$ & & $1.29(1.04-1.60)$ & 0.02 \\
\hline \multicolumn{6}{|l|}{ Death from any cause } \\
\hline Before transition & $283(1.4)$ & $232(1.2)$ & & $1.21(1.02-1.44)$ & 0.03 \\
\hline Until end of study & $391(1.5)$ & $327(1.3)$ & & $1.19(1.03-1.38)$ & 0.02 \\
\hline \multicolumn{6}{|c|}{ Primary outcome, revascularization or hospitalization for CHF } \\
\hline Before transition & $931(5.3)$ & $955(5.4)$ & & $0.96(0.88-1.06)$ & 0.43 \\
\hline Until end of study & $1,159(5.2)$ & $1,229(5.5)$ & & $0.93(0.86-1.01)$ & 0.09 \\
\hline \multicolumn{6}{|c|}{$\begin{array}{l}\text { Fatal myocardial infarction, nonfatal myocardial infarction, } \\
\text { or unstable angina }\end{array}$} \\
\hline Before transition & $439(2.3)$ & $490(2.6)$ & & $0.38(0.77-1.00)$ & 0.05 \\
\hline Until end of study & $580(2.4)$ & $627(2.6)$ & & $0.90(0.81-1.01)$ & 0.08 \\
\hline \multicolumn{6}{|l|}{ Fatal or nonfatal stroke } \\
\hline Before transition & $78(0.4)$ & $80(0.4)$ & & $0.97(0.71-1.33)$ & 0.85 \\
\hline Until end of study & $91(0.4)$ & $106(0.4)$ & 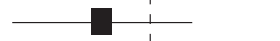 & $0.86(0.65-1.13)$ & 0.27 \\
\hline \multicolumn{6}{|l|}{ Fatal or nonfatal CHF } \\
\hline Before transition & $189(1.0)$ & $158(0.8)$ & & $1.19(0.96-1.47)$ & 0.11 \\
\hline \multirow[t]{4}{*}{ Until end of study } & $232(0.9)$ & $212(0.9)$ & & $1.09(0.91-1.32)$ & 0.35 \\
\hline & & \lceil & 1 & $\neg$ & \\
\hline & & 0.50 & 1.00 & 2.00 & \\
\hline & \multicolumn{5}{|c|}{$\begin{array}{c}\text { Intensive therapy } \\
\text { better }\end{array}$} \\
\hline
\end{tabular}

Fig. 2. HR for prespecified primary and secondary outcomes [with permission from ref. 4]. 
targeted low HbAlc levels, other patients with a shorter duration of type 2 diabetes mellitus and without established atherosclerosis or few and well-controlled risk factors still might benefit from intensive glycaemic control.

\section{Emerging Concepts: Insulin Resistance as a Prediabetic Risk Factor for Stroke}

Although diabetes mellitus increases the risk for cardiovascular complications twofold including stroke subtypes and death attributed to other vascular causes, different to what we learned from other risk factors such as LDL cholesterol, intensive modification of targeted HbAlc levels does not result in a sustained benefit with reduced mortality and stroke morbidity. This may be due to a more complex interaction of metabolic abnormalities developing in people without diabetes over decades, who are at risk to develop manifest type 2 diabetes mellitus. This condition is called metabolic syndrome, a constellation of vascular risk factors and metabolic disorders such as obesity, dyslipidemia, hypertension and hypoglycaemia, which all together appears to promote the development of atherosclerosis and as a final pathway type 2 diabetes mellitus. It is characterized by the insufficiency of a normal amount of insulin to produce a normal physiological response because of diminished sensitivity of target cells, such as in muscles. Once insulin binds to the receptors of target cells, transportation of glucose into the cell is insufficient which leads to defective synthesis of muscle glycogen [11]. Probably associated with other environmental factors such as lack of physical exercise and obesity, insulin resistance may develop in genetically predisposed individuals in combination with other cardiovascular risk factors. In contrast to many people without insulin resistance this group of patients who develop the metabolic syndrome also lack the positive effects of insulin which can act through antiatherogenic properties directly and hence reduce the risk to develop stroke and transient ischaemic attack.

Strategies to improve insulin sensitivity are important: they include physical exercise, weight loss and perhaps insulin sensitizing drugs (e.g. metformin, rosiglitazone, pioglitazone). Mediterranean food and restrictive alcohol consumption may also be beneficial. Whether or not insulin sensitizing drugs - finally reducing hypoglycaemic metabolic conditions in prediabetic patients may have additional protective effects, such as decreasing systemic inflammation, improving metabolic cellular control and dyslipidaemia, as well as to reduce the prothrombotic state along with antiatherogenic activities in the vascular endothelium, remains to be demonstrated. However, some of these drugs have been shown to cause significant side effects (e.g. rosiglitazone increased heart failure and fracture risks by $30-40 \%$ ). In contrast, a metaanalysis of 19 RCTs comparing pioglitazone with placebo in 16,319 patients with diabetes demonstrated that myocardial infarction and stroke occurred in only 375 of 8,554 patients $(4.4 \%)$ who received pioglitazone versus 450 of 7,836 patients (5.7\%) in the control arm (HR 0.82, $95 \%$ CI $0.72-0.94 ; \mathrm{p}=0.005)$. A non-significant trend towards increased serious heart failure was reported in $2.3 \%$ of the pioglitazone-treated patients compared to $1.8 \%$ of the control patients [12]. Whether or not insulin resistance is an independent risk factor or a prediabetic condition for stroke remains to be seen. At present we have to wait for ongoing studies such as the Insulin Resistant Intervention after Stroke (IRIS) trial which aims to determine whether pioglitazone prevents recurrent stroke or myocardial infarction during a 3-year period among more than 3,000 non-diabetic people who are insulin-resistant and have had a recent transient ischaemic attack or ischaemic stroke.

\section{References}

1 Emerging Risk Factors Collaboration: Diabetes mellitus, fasting blood glucose concentration, and risk of vascular disease: a collaborative meta-analysis of 102 prospective studies. Lancet 2010;375:2215-2222.

-2 Selvin E, Steffes MW, Hong Zhu BS, et al: Glycated hemoglobin, diabetes, and cardiovascular risk in nondiabetic adults. N Engl J Med 2010; 362:800-811.

3 Action to Control Cardiovascular Risk in Diabetes Study Group: Effects of intensive glucose lowering in type 2 diabetes. N Engl J Med 2008;358:2545-2559.

4 The ACCORD Study Group: Long-term effects of intensive glucose lowering on cardiovascular outcomes. N Engl J Med 2011;364:818-828.

5 Holman RR, Paul SK, Bethel MA, et al: 10-Year follow-up of intensive glucose control in type 2 diabetes. N Engl J Med 2008;359:1577-1589.

-6 Diabetes Control and Complications Trial Research Group: The effect of intensive treatment of diabetes on the development and progression of long-term complications in insulin-dependent diabetes mellitus. N Engl J Med 1993;329:977-986.

7 The UK Prospective Diabetes Study (UKPDS) Group: Intensive bloodglucose control with sulphonylureas or insulin compared with conventional treatment and risk of complications in patients with type 2 diabetes (UKPDS 33). Lancet 1998;352:837-853.

-8 Ismail-Beigi F, Craven T, Banerji MA, et al: Effect of intensive treatment of hyperglycaemia on microvascular outcomes in type 2 diabetes: an analysis of the ACCORD randomised trial. Lancet 2010;376:419-430.

-9 ADVANCE Collaborative Group: Intensive blood glucose control and vascular outcomes in patients with type 2 diabetes. N Engl J Med 2008; 358:2560-2572.

10 Duckworth W, Abraira C, Moritz T, et al: Intensive glucose control and complications in American veterans with type 2 diabetes. N Engl J Med 2009;360:129-139.

11 Kernan WN, Inzucchi SE, Viscoli CM, et al: Insulin resistance and risk for stroke. Neurology 2002;59:809-815. 
12 Lincoff AM, Wolski K, Nicholls SJ, et al: Pioglitazone and risk of cardiovascular events in patients with type 2 diabetes mellitus: a metaanalysis of randomised trials. JAMA 2007;298:1180-1188.

Prof. Dr. M.G. Hennerici

Department of Neurology, UMM, University of Heidelberg

Theodor-Kutzer-Ufer 1-3

DE-68135 Mannheim (Germany)

Tel. +496213832885

E-Mail hennerici@neuro.ma.uni-heidelberg.de

\section{4 Lifestyle Factors and the Risk of Stroke}

D.A. Kanhaia , F.L.J. Visseren ${ }^{a}$, A. Algra ${ }^{b-d}$, L.J. Kappelle ${ }^{c, d}$

aDepartment of Vascular Medicine, b Julius Center for Health Sciences and Primary Care, 'Department of Neurology and Neurosurgery, and dUtrecht Stroke Centre, Rudolf Magnus Institute of Neuroscience, University Medical Center Utrecht, Utrecht, The Netherlands

Prevention of stroke has a larger impact on the health and welfare of the population than any treatment of proven value that can be administered after the stroke has occurred. For the prevention of stroke, modification of lifestyle factors has more impact than the prescription of medication or any other preventive procedure. In a recent landmark study ten risk factors, including lifestyle factors, have been identified that account for $90 \%$ of the population-attributable risk (PAR) for stroke [1].

Lifestyle factors that have been associated with an increased risk of stroke include smoking, obesity, decreased physical activity, stress, alcohol intake and specific dietary patterns. Literature concerning these risk factors predominantly has focussed on first manifestation of stroke. In this paper, we put existing evidence in perspective by adding information from our Second Manifestations of ARTerial disease (SMART) cohort [2, 3]. This hospital-based cohort includes 1,091 patients with a recent diagnosis of transient ischaemic attack (TIA) or minor ischaemic stroke with a median follow-up of 5.5 years (table 1).

\section{Smoking}

In the INTERSTROKE study smokers had a 2.09fold (95\% confidence interval, 95\% CI: 1.75-2.51) higher risk for ischaemic stroke and a 1.45-fold (95\% CI: 1.09 1.96) higher risk for haemorrhagic stroke as compared to non-smokers [1]. The PAR was estimated to be $19 \%$ [1]. There was a linear association between the number
Table 1. Baseline characteristics of patients with a recent TIA or minor ischaemic stroke in the SMART study

\begin{tabular}{lc}
\hline & $\begin{array}{c}\text { SMART cohort } \\
(\mathrm{n}=1,091)\end{array}$ \\
\hline Male gender & $749(69)$ \\
Age, years & $61 \pm 11$ \\
Body mass index & $26.3 \pm 3.8$ \\
Waist circumference, cm & $94 \pm 12$ \\
Waist-to-hip ratio & $0.54 \pm 0.76$ \\
Blood pressure, mm Hg & \\
$\quad$ Systolic & $145 \pm 24$ \\
$\quad$ Diastolic & $83 \pm 12$ \\
Type 2 diabetes & $166(15)$ \\
Metabolic syndrome & $390(36)$ \\
History of vascular disease & \\
Coronary artery disease & $166(15)$ \\
Peripheral arterial disease & $64(6)$ \\
Aneurysm of the aorta & $32(3)$ \\
Smoking & \\
$\quad$ Never & $177(18)$ \\
Ever & $447(46)$ \\
Current & $346(36)$ \\
Medication & \\
Blood pressure-lowering agents & $593(55)$ \\
Glucose-lowering agents & $132(12)$ \\
Lipid-lowering agents & $632(58)$ \\
Oral anticoagulants & $111(10)$ \\
\hline & $902(83)$ \\
\hline
\end{tabular}

Values are mean $\pm \mathrm{SD}$ or $\mathrm{n}(\%)$.

${ }^{1}$ Defined according to National Cholesterol Education Program ATPIII-revised guidelines.

of cigarettes smoked and these risks. In the SMART cohort, smokers who suffered from a TIA or minor stroke had twice the risk for subsequent stroke than nonsmokers (hazard ratio, HR, for ischaemic stroke: 2.03; 95\% CI: 0.99-4.16, and HR for all stroke: 1.87; 95\% CI: 0.96-3.64). Patients with a recent TIA or minor stroke in the upper quartile of pack years of smoking had a 2.38-fold (95\% CI: 1.18-4.76) increased risk for ischaemic stroke, and a 2.07 -fold increased risk (95\% CI: 1.10-3.89) for all stroke when compared with those in the lower quartile.

Evidence regarding the impact of cessation of smoking on subsequent vascular events after TIA or minor ischaemic stroke is lacking. In patients with a recent acute coronary syndrome, the risk of death, myocardial infarction (MI) or stroke during the first 6 months was reduced by a quarter if patients quit smoking (odds ratio, OR: 0.74; 95\% CI: 0.53-1.02) [4]. 


\section{Obesity}

A large meta-analysis showed that obese persons, defined as body mass index (BMI) $>30$, had a 1.64-fold ( $95 \%$ CI: 1.36-1.99) increased risk of ischaemic stroke [5]. For haemorrhagic stroke, this association was less outspoken (OR: 1.24; 95\% CI: 0.99-1.54). The PAR was estimated to be $27 \%$ [1]. Abdominal obesity probably is the most important factor for this increased risk as waist-to-hip ratio has a more outspoken relationship with stroke than the BMI [1].

Current guidelines indicate obesity as a modifiable risk factor for secondary prevention of stroke, mainly based upon its interaction with other potent risk factors [6]. Abdominal or general obesity is not an independent risk factor for the recurrence of ischaemic stroke [3]. There are no data about the effects of weight modification in the context of secondary prevention after TIA or minor stroke.

\section{Inactivity}

Regular physical activity is associated with a reduced risk of stroke (OR: 0.69; 95\% CI: 0.53-0.90) [1], possibly because it can reduce body weight, blood pressure, blood viscosity, fibrinogen concentration and platelet aggregability. Moreover, it might decrease insulin resistance, regulate lipid metabolism and improve endothelial function.

Analyses from the SMART cohort showed that patients who reported to participate in sports have a $43 \%$ (95\% CI: 1-67) lower risk of a subsequent stroke than patients without regular physical activity.

The effects of introducing exercise on the occurrence of future vascular complications as part of secondary prevention after a TIA are unknown. The risk of death, MI or stroke during the first 6 months after an acute coronary syndrome was lower in patients with than in patients without regular physical activity (OR: 0.69; 95\% CI: 0.54-0.69) [4].

\section{Alcohol}

The association between alcohol consumption and the risk of haemorrhagic stroke is linear, whereas the association with ischaemic stroke shows a J-shaped curve, with the lowest risk at a consumption of one or two drinks per day and the highest risk with alcohol abuse. A meta- analysis showed that consumers of one or two drinks per day have a lower risk of ischaemic stroke than abstainers (relative risk, RR: 0.72; 95\% CI: 0.57-0.91) [7]. Intake of four or more beverages per day results in an increased risk for both ischaemic (RR: 1.69; 95\% CI: 1.34-2.15) and haemorrhagic (RR: 2.18 ; 95\% CI: 1.48-2.20) stroke. The most plausible explanation for the association between alcohol intake and the risk of stroke is its relationship with blood pressure.

No data is available regarding the change of alcohol consumption and the risk of subsequent stroke or any secondary vascular event.

\section{Stress}

In the INTERSTROKE study psychosocial stress was associated with a 1.3-fold (95\% CI: 1.06-1.60) increased risk of stroke [1]. The PAR was estimated to be $4.6 \%$ [1]. Compared with those without a major life event (MLE), acquiring more than one MLE accompanied a 1.53 -fold (95\% CI: 1.11-2.10) increased risk of stroke [8]. There are no studies assessing the role of stress after a TIA or minor stroke.

\section{Diet}

Intake of vegetables, fruit, whole grain foods, fish and a Mediterranean diet has been described to reduce the risk of vascular events [9]. Currently, there is no evidence that improving diet would reduce the risk of recurrent stroke. Dietary modification had a modest beneficial effect on the risk of death, MI or stroke during the first 6 months after an acute coronary syndrome (OR: 0.91; $95 \%$ CI: 0.77-1.07) [4]. Supplementation of antioxidants such as $\beta$-carotene or vitamin $E$ does not benefit patients with vascular disease [10]. Daily administration of folic acid, vitamin $B_{6}$, and vitamin $B_{12}$ to patients with recent stroke or TIA did not reduce the incidence of major vascular events [11]. Other changes of diet have not been investigated in patients with a recent TIA or minor stroke.

\section{Combination of Healthy Lifestyle Factors}

An overall healthy lifestyle, including the combination of not smoking, eating a healthful diet, consumption of modest amounts of alcohol, exercising and maintaining optimal body weight, is probably more beneficial for the 
reduction of vascular events than the accumulated influence of each of the individual factors. The Health Professionals Follow-Up Study showed an inverse linear relationship between the number of healthy lifestyle factors and the risk of a first-ever stroke [12]. The PAR for ischaemic stroke of these five healthy lifestyle factors was 52\% (95\% CI: 19-75) in men and 54\% (95\% CI: 15-78) in women [12].

There are no large studies with specific focus upon the combination of major lifestyle alterations and their effect on recurrent stroke. The combination of a healthy diet and regular exercise after an acute coronary syndrome reduced the risk of subsequent vascular events more $(\mathrm{OR}$ : 0.46; 95\% CI: $0.38-0.57)$ than the separate influence of a healthy diet (OR: $0.91 ; 95 \%$ CI: $0.77-1.17)$ or regular exercise (OR: 0.69; 95\% CI: 0.54-0.89) [4].

\section{Perspective}

The importance of a healthy lifestyle has been emphasized extensively in guidelines in the context of primary and secondary prevention of vascular diseases [6]. Nevertheless, there is no solid evidence that lifestyle modification after a TIA or minor stroke would reduce the risk of recurrent stroke or death. Recently, adiposity has shown to have a different influence on the risk of stroke in secondary prevention compared to primary prevention [3]. Moreover, obese stroke survivors have better early and long-term mortality outcomes, including secondary stroke, when compared with stroke survivors with a normal BMI [13]. A possible explanation for this paradoxical discrepancy could be index event bias [14]. Another explanation may be that patients with higher BMI have greater metabolic reserve that protects them from further vascular complications of a prior stroke.

There is no randomized clinical trial that has evaluated the effect of combined modification of lifestyle factors on the risk of stroke recurrence. It is unlikely that such a trial will be performed since it will probably be considered unethical not to advocate a healthy lifestyle. Nevertheless, specific diets easily can be investigated in a clinical trial. A trial of active obesity management would be useful to determine the effect of weight reduction on the risk of subsequent stroke. In the meantime it seems appropriate for patients who have suffered from a TIA or minor stroke to reduce their risk of recurrent stroke and other serious vascular events by adapting a healthy lifestyle. Physicians should encourage their patients to realize this, but should keep an open mind for research aimed to prove the validity of current guidelines.

\section{References}

-1 O’Donnell MJ, Xavier D, Liu L, Zhang H, Chin SL, Rao-Melacini P, Rangarajan S, Islam S, Pais P, McQueen MJ, Mondo C, Damasceno A, Lopez-Jaramillo P, Hankey GJ, Dans AL, Yusoff K, Truelsen T, Diener HC, Sacco RL, Ryglewicz D, Czlonkowska A, Weimar C, Wang X, Yusuf $\mathrm{S}$ : Risk factors for ischaemic and intracerebral haemorrhagic stroke in 22 countries (the INTERSTROKE study): a case-control study. Lancet 2010;376:112-123.

-2 Simons PC, Algra A, van de Laak MF, Grobbee DE, van der Graaf Y: Second manifestations of ARTerial disease (SMART) study: rationale and design. Eur J Epidemiol 1999;15:773-781.

3 Kanhai DA, Kappelle LJ, van der Graaf Y, Uiterwaal CS, Visseren FLJ: The risk of general and abdominal adiposity in the occurrence of new vascular events and mortality in patients with various manifestations of vascular disease. Int J Obes (Lond) 2011, E-pub ahead of print.

4 Chow CK, Jolly S, Rao-Melacini P, Fox KA, Anand SS, Yusuf S: Association of diet, exercise, and smoking modification with risk of early cardiovascular events after acute coronary syndromes. Circulation 2010;121:750-758.

5 Strazzullo P, D’Elia L, Cairella G, Garbagnati F, Cappuccio FP, Scalfi L: Excess body weight and incidence of stroke: meta-analysis of prospective studies with 2 million participants. Stroke 2010;41:e418-e426.

6 European Stroke Organisation (ESO) Executive Committee; ESO Writing Committee: Guidelines for management of ischaemic stroke and transient ischaemic attack 2008. Cerebrovasc Dis 2008;25:457-507.

$>7$ Reynolds K, Lewis B, Nolen JD, Kinney GL, Sathya B, He J: Alcohol consumption and risk of stroke: a meta-analysis. JAMA 2003;289:579588.

-8 Kornerup H, Osler M, Boysen G, Barefoot J, Schnohr P, Prescott E: Major life events increase the risk of stroke but not of MI: results from the Copenhagen City Heart Study. Eur J Cardiovasc Prev Rehabil 2010;17: 113-118.

-9 Bazzano LA, Serdula MK, Liu S: Dietary intake of fruits and vegetables and risk of cardiovascular disease. Curr Atheroscler Rep 2003;5:492499.

10 Bjelakovic G, Nikolova D, Gluud LL, Simonetti RG, Gluud C: Antioxidant supplements for prevention of mortality in healthy participants and patients with various diseases. Cochrane Database Syst Rev 2008;CD007176.

11 VITATOPS Trial Study Group: B vitamins in patients with recent transient ischaemic attack or stroke in the VITAmins TO Prevent Stroke (VITATOPS) trial: a randomised, double-blind, parallel, placebo-controlled trial. Lancet Neurol 2010;9:855-865.

-12 Chiuve SE, Rexrode KM, Spiegelman D, Logroscino G, Manson JE, Rimm EB: Primary prevention of stroke by healthy lifestyle. Circulation. 2008;118:947-954.

13 Vemmos K, Ntaios G, Spengos K, Savvari P, Vemmou A, Pappa T, Manios E, Georgiopoulos G, Alevizaki M: Association between obesity and mortality after acute first-ever stroke: the obesity-stroke paradox. Stroke 2011;42:30-36.

14 Dahabreh IJ, Kent DM: Index event bias as an explanation for the paradoxes of recurrence risk research. JAMA 2011;305:822-823.

Prof. L.J. Kappelle, MD, $\mathrm{PhD}$

Department of Neurology, UMC Utrecht

G03.228, Heidelberglaan 100

NL-3584 CX Utrecht (The Netherlands)

Tel. +31 8875555 55, E-Mail l.kappelle@umcutrecht.nl 